\title{
Cannabis sativa and the endogenous cannabinoid system: therapeutic potential for appetite regulation
}

Article

Accepted Version

Farrimond, J. A., Mercier, M. S., Whalley, B. J. and Williams, C. M. (2011) Cannabis sativa and the endogenous cannabinoid system: therapeutic potential for appetite regulation. Phytotherapy Research, 25 (2). pp. 170-188. ISSN 0951-418X doi: https://doi.org/10.1002/ptr.3375 Available at https://centaur.reading.ac.uk/19932/

It is advisable to refer to the publisher's version if you intend to cite from the work. See Guidance on citing.

Published version at: http://onlinelibrary.wiley.com/doi/10.1002/ptr.3375/abstract

To link to this article DOI: http://dx.doi.org/10.1002/ptr.3375

Publisher: John Wiley \& Sons, Ltd

All outputs in CentAUR are protected by Intellectual Property Rights law, including copyright law. Copyright and IPR is retained by the creators or other copyright holders. Terms and conditions for use of this material are defined in the End User Agreement.

www.reading.ac.uk/centaur 
Central Archive at the University of Reading

Reading's research outputs online 


\section{Cannabis sativa and the endogenous cannabinoid system:}

\section{2 therapeutic potential for appetite regulation}

3 Short title: A therapeutic role for C. sativa in appetite regulation

4 Jonathan A. Farrimond ${ }^{1,2}$, Marion S. Mercier ${ }^{1,2}$, Benjamin J. Whalley ${ }^{1}$ and Claire

5 M. Williams ${ }^{2}$.

6

$7 \quad{ }^{1}$ School of Pharmacy and ${ }^{2}$ School of Psychology and Clinical Language Sciences,

8 University of Reading.

9

10 Corresponding author: Jonathan Farrimond (j.a.farrimond@ @reading.ac.uk)

11 School of Pharmacy,

12 University of Reading,

13 Whiteknights,

14 Reading,

15 Berkshire,

16 RG6 6AP,

17 U.K.

18 Phone: +44 (0)118 3788464

19 Fax: +44 (0)118 3784703

20

21

22 This research was supported in part by the University of Reading Research Endowment 23 Trust Fund (to JAF). 


\section{$1 \quad$ Abstract}

2 The herb Cannabis sativa ( $C$. sativa) has been used in China and on the Indian

3 subcontinent for thousands of years as a medicine. However, since it was brought to the

4 U.K. and then the rest of the western world in the late $19^{\text {th }}$ century, its use has been a

5 source of controversy. Indeed, its psychotropic side effects are well reported but only

6 relatively recently has scientific endeavour begun to find valuable uses for either the

7 whole plant or its individual components. Here, we discuss evidence describing the

8 endocannabinoid system, its endogenous and exogenous ligands and their varied effects

9 on feeding cycles and meal patterns. Furthermore we also critically consider the

10 mounting evidence which suggests non- $\Delta^{9}$ tetrahydrocannabinol phytocannabinoids play

11 a vital role in $C$. sativa-induced feeding pattern changes. Indeed, given the wide range

12 of phytocannabinoids present in $C$. sativa and their equally wide range of intra-, inter-

13 and extra-cellular mechanisms of action, we demonstrate that non-

$14 \Delta^{9}$ tetrahydrocannabinol phytocannabinoids retain an important and, as yet, untapped

15 clinical potential.

16

17 Keywords: Feeding, appetite, phytocannabinoid, endocannabinoid,

$18 \Delta \Delta^{9}$ tetrahydrocannabinol

19

20 


\section{Introduction}

2 For $\sim 10,000$ years, Cannabis sativa ( $C$. sativa) has been used medicinally and

3 recreationally for its diverse pharmacological actions and psychotropic properties.

4 Typical actions include sedation, analgesia, hypothermia, catalepsy and euphoria which

5 are thought to arise mainly from cannabinoid type 1 receptor $\left(\mathrm{CB}_{1} \mathrm{R}\right)$ activation

6 (Childers et al., 1998; Little et al., 1988). These effects have typically been ascribed to

7 the sixty (Howlett, 2002; Pertwee, 2008b) to eighty (Izzo et al., 2009)

8 phytocannabinoids (pCBs) present in $C$. sativa. In more recent times, $C$. sativa has been

9 used less widely for medicinal purposes, due in part to the development of other

10 therapeutic agents with better side effect profiles (e.g. Tramer et al., 2001). Indeed,

11 cannabinoid side-effects are known to include reduced motor coordination, tachycardia,

12 transient memory loss, disruption to the sense of time, cognitive impairments, anxiety

13 and a disruption of appetite regulation (Childers et al., 1998; Dewey, 1986; Grant et al.,

14 2005; Hollister, 1986; Kirkham et al., 2001b; Wilkinson et al., 2003) (for a recent

15 review on the safety of $C$. sativa-based therapy see Wang et al., 2008). However, the

16 relatively recent identification of the $C_{1} R$ and cannabinoid type $2\left(C_{2} R\right)$ receptors,

17 alongside the subsequent characterisation of the endocannabinoid (eCB) system (for a

18 recent review see Maccarrone, 2009), has driven a resurgence of interest in the potential

19 applications of cannabinoid-based therapy. Cannabinoid therapies have now been

20 investigated for a wide range of neurological and neurodegenerative disorders (Glass,

21 2001; Pryce et al., 2003), both in terms of treatment (for a review see Consroe, 1998)

22 and/or symptom management (Davis et al., 2007). One notable example is in the

23 treatment of multiple sclerosis (Pryce et al., 2005) and its symptoms (eg. spasticity), for 
1 which a cannabis-based compound (Sativex ${ }^{\circledR}$ ) has recently been licensed in the U.K.,

2 Spain and Canada by GW Pharmaceuticals.

'Cannabinoid' is a well-known term used to describe the compounds isolated

4 from $C$. Sativa, the pCBs such as $\Delta^{9}$ tetrahydrocannabinol ( $\Delta^{9}$ THC), cannabidiol (CBD)

5 and cannabinol (CBN). In addition to these, the term now also encompasses both

6 synthetic exogenous (e.g. SR141716A, a $\mathrm{CB}_{1} \mathrm{R}$ specific antagonist/inverse agonist) and

7 endogenously produced ligands (the eCBs anandamide (AEA) and 2-arachidonyl

8 glycerol (2-AG)) at $\mathrm{CB}_{1}-$ and $\mathrm{CB}_{2} \mathrm{Rs}$ (for an overview of the cannabinoid receptor

9 (CBR) ligands referred to in this review, see table 1). The development and

10 characterisation of such pharmacological tools has enabled significant progress to be

11 made into understanding the eCB system over the last 20 years (Onaivi et al., 2002).

$12 \Delta^{9} \mathrm{THC}$, the main psychoactive component in $C$. sativa, was first isolated and

13 synthesised in 1964 by Gaoni et al. (Gaoni et al., 1964a). However, it was not until

141988 that the first cannabinoid specific G-protein coupled receptor $\left(\mathrm{GPCR} ; \mathrm{CB}_{1} \mathrm{R}\right)$ at

15 which it acts was characterised (Devane et al., 1988; Matsuda et al., 1990), lending

16 credence to the postulated existence of an eCB system (Howlett et al., 1990) (for review

17 see Pertwee, 2005). A series of studies (Herkenham et al., 1991; Herkenham et al.,

18 1990) identifying the widespread expression of this receptor in the brain further

19 supported this discovery. These findings were rapidly followed by the isolation and

20 structural determination of the first eCB ligand, AEA, in 1992 (Devane et al., 1992), the

21 identification and characterisation of $\mathrm{CB}_{2} \mathrm{R}$ expressed on immune cells, in 1993 (Munro

22 et al., 1993), and the identification of a second eCB ligand, 2-AG, in 1995 (Mechoulam

23 et al., 1995b; Sugiura et al., 1995) (See Fig.1). Since then, significant academic and

24 commercial effort has been invested in characterising and exploiting the eCB system 
1 (for example reviews see Basavarajappa, 2007a; Basavarajappa, 2007b; Bisogno et al., 2 2005; Freund et al., 2003).

As previously outlined, it is now apparent that the eCB system is physiologically ubiquitous and linked to many pathophysiological states (de Fonseca, 2005), resulting in its identification as a therapeutic target, as well as the publication of numerous reviews regarding the potential benefits of cannabinoid based therapies (e.g. Agrawal et al.,

7 2009; Baker et al., 2003; Glass, 2001; Goutopoulos et al., 2002; Makriyannis et al.,

8 2005). This is particularly true in the field of body weight regulation and energy balance

9 (Yates et al., 2009), where significant advances have been made in the development of 10 both anti-anorectic (e.g. in hepatitis C (Costiniuk et al., 2008); in cancer (Walsh et al., 11 2003); in human immunodeficiency virus (HIV) (Woolridge et al., 2005)) and antiobesity (Van Gaal et al., 2005) cannabinoid-based therapies. However, these advances must be made with care (Grant et al., 2005), and it is clear that further long-term studies are warranted if the safety profiles of such therapies are to be fully understood (Wang et al., 2008). Indeed, the withdrawal of Acomplia (Rimonabant: SR141716A; see EMA, 2009 for details) from clinical use for the treatment of obesity due to serious cognitive side effects, combined with the cessation of Phase III clinical trials for a second putative anti-obesity drug, Taranabant (MK-0364; Clark, 2009), illustrates the difficulties of manipulating such a complex and ubiquitous system. Nonetheless, it is clear that the

20 eCB system plays an important, if not yet fully understood, role in appetite, obesity and energy balance (for reviews see Cota et al., 2003a; Kirkham, 2008). This review will describe the significant progress made, as well as the work still required, in order to fully understand the role played by the eCB system in feeding and appetite regulation.

24 Importantly, by focusing on those studies that have examined pCB effects and how they 
1 might interact with the $\mathrm{eCB}$ system to modulate appetite and feeding, this review 2 provides insight into the potential use of these compounds as therapeutic tools in the 3 treatment of eating- and weight-related disorders.

4

5

6 


\section{The endocannabinoid system in the central nervous system}

2 Although, CBRs are present in both the peripheral and central nervous systems (CNS),

3 the majority of cannabinoid feeding research to date has focused primarily on centrally-

4 mediated feeding mechanisms, a focus that is consequently reflected in this review. A

5 short section outlining the biological components that comprise the eCB system within

6 the CNS is presented hereafter (see also figures 2 and 3).

ECBs (AEA and 2-AG) are produced on demand by postsynaptic neurons (Di

8 Marzo et al., 2004) in the CNS in response to rises in intracellular $\left[\mathrm{Ca}^{2+}\right]$ (Cadas et al.,

9 1997; Di Marzo et al., 1994). Such increases typically occur following $\mathrm{G}_{\mathrm{q}}$-coupled

10 receptor activation which stimulates production of inositol trisphosphate $\left(\mathrm{IP}_{3}\right)$ by

11 phospholipase $\mathrm{C}$ (PLC) leading to a release of $\mathrm{Ca}^{2+}$ from intracellular stores (for 12 reviews see Berridge, 1995; Berridge et al., 1988; Putney Jr, 1986). Alternatively, 13 ionotropic glutamate receptor activation permits the influx of $\mathrm{Ca}^{2+}$ to increase eCB 14 production (Freund et al., 2003).

AEA synthesis from its precursors, arachidonic acid and $\mathrm{N}$-arachidonoyl

16 phosphatidyl-ethanolamine (NaPE) is an on demand effect. Phosphatidylethanolamine is

17 first catalysed by $\mathrm{Ca}^{2+}$-dependent $\mathrm{N}$-acyltransferase (Cadas et al., 1997) into $\mathrm{NaPE}$

18 (although $\mathrm{Ca}^{2+}$-independent processes have also been proposed; Jin et al., 2007); NaPE

19 is then converted to the $\mathrm{N}$-acylethanolamine, AEA, (Di Marzo et al., 1994) by NaPE

20 phospholipase-D (Okamoto et al., 2004). However, it has been suggested that at least

21 three other pathways for AEA synthesis may also exist (for reviews, see Liu et al.,

22 2008; Okamoto et al., 2009a; Okamoto et al., 2009b). 2-AG is formed by the

23 diacylglycerol (DAG) lipases $\alpha$ and $\beta$-catalyzed hydrolysis of DAG (Di Marzo et al., 24 2007). After formation, eCB release into the extracellular space is thought to occur 
1 immediately via passive diffusion or through a putative $\mathrm{eCB}$ transporter as no storage

2 systems for eCBs have yet been identified and some eCB precursors are known to be

3 membrane bound, suggesting that $\mathrm{eCBs}$ are produced at their release site (Di Marzo,

4 2008; Pope et al, 2010.).

Once released into the intercellular space, unlike classical neurotransmission,

6 eCB signalling is retrograde such that eCBs released from a postsynaptic neuron diffuse

7 across the synaptic cleft to bind with presynaptically located $\mathrm{CB}_{1}$ Rs to exert effects (see

8 figure 3; Ohno-Shosaku et al., 2001; Piomelli et al., 2000; Wilson et al., 2001) that are

9 now thought to be intimately linked to synaptic plasticity (see Alger, 2009). The

10 activation of presynaptic $\mathrm{CB}_{1} \mathrm{Rs}$ by $\mathrm{AEA}$ and $2-\mathrm{AG}$ induces a PLC- $\beta$-mediated

11 suppression of $\left[\mathrm{Ca}^{2+}\right]$ entry and a protein kinase A (PKA)-mediated upregulation of $\left[\mathrm{K}^{+}\right]$

12 efflux, thereby driving neuronal resting membrane potential to more hyperpolarized

13 values and so reducing the further pre-synaptic release of neurotransmitter (for review

14 see Mackie, 2006; Südhof et al., 2008). Indeed, presynaptically it has been conclusively

15 demonstrated that $\mathrm{CB}_{1} \mathrm{R}$ activation has a direct effect on membrane polarisation, for

16 example, in cultured hippocampal neurones (Deadwyler et al., 1995; Schweitzer, 2000)

17 and in CA1 pyramidal cells (Kirby et al., 2000).

18 ECB reuptake however remains the subject of much debate. Fatty acid amide

19 hydrolase (FAAH; Cravatt et al., 1996) and monoacylglycerol lipase (MAGL; Lambert

20 et al., 2005) are the two main enzymes involved in eCB degradation, and have been

21 known to degrade AEA and 2-AG for some time. However, although a specific

22 transmembrane transporter protein has yet to be identified, it seems that reuptake may

23 be a rapid carrier-mediated transport process (e.g. Gerdeman et al., 2002; Ronesi et al.,

24 2004) since eCBs within the synaptic cleft are almost immediately inactivated (Di 
1 Marzo et al., 2007). 2-AG is typically inactivated by MAGL (Di Marzo, 2008) but also

2 to some extent by FAAH (Blankman et al., 2007), whereas, AEA is thought to be

3 degraded by FAAH alone (Vandevoorde, 2008). Four mechanisms are currently

4 proposed to underlie eCB reuptake; a membrane-localised transmembrane carrier

5 protein, FAAH-induced passive diffusion through the lipid bilayer, the creation of

6 caveolae with AEA binding sites on the cell membrane which then internalise AEA

7 and/or 2-AG, and via intracellular sequestration into the cell within a lipid shell (for a

8 recent review see Yates et al., 2009). Intracellular FAAH-mediated AEA hydrolysis

9 creates arachidonic acid and ethanolamine (Deutsch et al., 2002 thoroughly review the

10 biochemistry of FAAH) whilst 2-AG undergoes primarily MAGL-mediated hydrolysis

11 into arachidonic acid and glycerol (Blankman et al., 2007).

12 While the mechanisms involved in AEA and 2-AG degradation remain poorly

13 understood, it is clear that FAAH and MAGL blockade could be of therapeutic value.

14 FAAH inhibition, for instance by URB597 (Piomelli et al., 2006; see Vandevoorde,

152008 for a review of FAAH and MAGL inhibitors), is expected to potentiate AEA

16 effects (and to some extent 2-AG). Such inhibition could, for instance, be expected to

17 have effects on energy homeostasis as AEA and 2-AG administration into the

18 hypothalamic nuclei has been conclusively demonstrated to induce hyperphagia in rats

19 (Jamshidi et al., 2001; Kirkham et al., 2001a; Kirkham et al., 2002). Consequently,

20 increasing AEA concentrations in the synaptic cleft via FAAH inhibition could produce

21 similar effects. Although MAGL inhibition (e.g. by URB602; King et al., 2007) which

22 could potentiate 2-AG effects is less well studied than FAAH inhibition, it too could be

23 of comparable therapeutic use. It is however important to consider that both FAAH and

24 MAGL inhibition could have secondary effects besides increasing AEA and 2-AG 
1 levels respectively. For instance, some evidence suggests that FAAH inhibition can also

2 decrease 2-AG levels (see Di Marzo et al., 2008 for a review of these data), and MAGL

3 inhibition, by the particularly potent and selective MAGL inhibitor JZL-184, has been

4 found to induce behavioural effects similar to those produced by agonist-induced $\mathrm{CB}_{1} \mathrm{R}$

5 activation (Long et al., 2009). The dynamic interplay between these systems must be

6 taken into account when considering new therapeutic approaches if unwanted side-

7 effects are to be minimised.

8 The cannabinoid receptors, $\mathrm{CB}_{1}$ and $\mathrm{CB}_{2} \mathrm{R}$, are members of the superfamily of

9 GPCRs and are characterised by seven transmembrane helices (Turu et al., 2009). $\mathrm{CB}_{1} \mathrm{R}$

10 was cloned in 1990 (Matsuda et al., 1990), 26 years after the isolation of $\Delta^{9} \mathrm{THC}$.

$11 \mathrm{CB}_{2} \mathrm{Rs}$ were first identified and characterised via polymerised chain reaction 12 experiments in 1993 (Munro et al., 1993; Onaivi et al., 2006), and were initially thought

13 to be present only in inflammatory/immune cells; Basavarajappa, 2007b; Munro et al., 14 1993), although evidence now shows $\mathrm{CB}_{2} \mathrm{R}$ expression in the brain (Gong et al., 2006;

15 Onaivi et al., 2006; Van Sickle et al., 2005). Indeed, it is now known that both $\mathrm{CB}_{1-}$ and $16 \mathrm{CB}_{2} \mathrm{Rs}$ are widely expressed in the brain (Gong et al., 2006; Moldrich et al., 2000) 17 although it is postulated that the majority of the functional eCB effects in the CNS are $18 \mathrm{CB}_{1} \mathrm{R}$ mediated (Piomelli, 2003). This receptor is one of the most abundant GPCRs in 19 the CNS (Herkenham et al., 1991) and its distribution within the mammalian brain 20 reflects the behavioural effects of cannabinoid administration. For instance, $\mathrm{CB}_{1} \mathrm{R}$ levels 21 are particularly high in the cortex, hippocampus, cerebellum and basal ganglia, correlating with the well-known effects of cannabinoids on cognition, memory and 23 motor control respectively. (Herkenham et al., 1991; Tsou et al., 1997; for a detailed 24 review of $\mathrm{CB}_{1} \mathrm{R}$ localisation see Mackie, 2005). Although also present in the 
1 hypothalamus, $\mathrm{CB}_{1} \mathrm{R}$ levels are lower in this brain region than in those mentioned above

2 (Herkenham et al., 1991; Tsou et al., 1997) which is somewhat surprising considering

3 the well-known hypothalamic involvement in feeding-related processes (Elmquist et al.,

4 1999). However, a study by Breivogel et al. found that hypothalamic $\mathrm{CB}_{1} \mathrm{Rs}$ are more

5 strongly coupled to G-proteins than those in numerous other brain regions including the

6 cortex and hippocampus (Breivogel et al., 1997), supporting important functional

7 effects of cannabinoids in this brain region, and suggesting that functional gain

8 associated with downstream intracellular signalling cascades following $\mathrm{CB}_{1} \mathrm{R}$ activation

9 may be of crucial importance.

10 While $\mathrm{CB}_{1^{-}}$and $\mathrm{CB}_{2} \mathrm{Rs}$ are thought to mediate the majority of cannabinoid

11 effects, both exo- and endo-genous cannabinoids also exert effects via other receptors.

12 In line with this, it has been conclusively demonstrated that the non-psychotropic

13 exogenous cannabinoids (excluding $\mathrm{CBN}$ and $\Delta^{9}$ tetrahydrocannabivarin; $\Delta^{9} \mathrm{THCV}$ )

14 exhibit almost no affinity for either $\mathrm{CB}_{1}$ or $\mathrm{CB}_{2} \mathrm{Rs}$ (Petrosino et al., 2009) and must

15 therefore exert their known pharmacological effects via other routes. A number of

16 alternative receptor sites are currently being investigated, including GPR55 (Brown et

17 al., 2001; Pertwee, 2007; Ryberg et al., 2007), GPR119 (Overton et al., 2006) and/or

18 receptor-coupled or receptor independent ion channels $(\mathrm{Oz}, 2006)$ (e.g. transient

19 receptor potential vanilloid $1 ; \mathrm{VR}_{1}$ ). The former two of these will briefly be reviewed

20 here since both GPR55 and GPR119 activation have been found to be involved in

21 aspects of feeding (for reviews of $\mathrm{CB}_{1}$ - and $\mathrm{CB}_{2} \mathrm{R}$-independent cannabinoid effects see

22 Brown, 2007; De Petrocellis et al., 2009).

23 GPR55, first identified by Sawzdargo in human brain and spleen and in rat

24 brain, spleen and intestine (Sawzdargo et al., 1999; for a gastrointestinal tract review 
1 see Sanger, 2007), is currently a putative third CBR. Upon activation, GPR55

2 suppresses $\mathrm{M}$-type $\mathrm{K}^{+}$currents and stimulates phosphatidylinositol 4,5-bisphosphate

3 (PIP2) -induced $\mathrm{Ca}^{2+}$ release from intracellular stores (Henstridge et al., 2009; Lauckner

4 et al., 2008). While the status of GPR55 as a CBR has been a topic of fierce academic

5 debate for some years (Petitet et al., 2006), somewhat more compelling evidence has

6 been presented recently suggesting that it is indeed a CBR (Baker et al., 2006;

7 Henstridge et al., 2010; Kapur et al., 2009; Lauckner et al., 2005; Pertwee, 2007; Ross,

8 2009; Ryberg et al., 2007; Staton et al., 2008). Both Baker (Baker et al., 2006) and

9 Ryberg (using radioligand binding assays in human embryonic kidney (HEK293) cells;

10 Ryberg et al., 2007) have shown that CP55,940 (a non-selective CBR agonist), but not

11 WIN55212-2 (a CBR agonist), binds with strong affinity to GPR55; Baker also showed that AEA, 2-AG and $\Delta^{9} \mathrm{THC}$ bind to this receptor. Moreover, Ryberg presented further

13 evidence in the same manuscript suggesting that GPR55 was $\mathrm{G}_{\alpha 13}$ coupled, and that the

14 comparatively late detection of GPR55 as a possible CBR was because the affinity of

$15 \mathrm{CP} 55940$ for GPR55 binding was 25 times lower than that for $\mathrm{CB}_{1} \mathrm{R}$ binding. However,

16 in a similar study Lauckner and colleagues (Lauckner et al., 2005) found that while

$17 \Delta^{9}$ THC could activate GPR55 in dorsal root ganglia (DRG) cells, neither WIN55212-2 nor CP55,940 bound to GPR55 in HEK293 and Chinese Hamster Ovary (CHO) cells.

19 Furthermore the observed effects were blocked by application of SR141716A, a $\mathrm{CB}_{1} \mathrm{R}$

20 specific antagonist, (although not by SR144528, a $\mathrm{CB}_{2} \mathrm{R}$ specific antagonist), suggesting

21 that these were $\mathrm{CB}_{1} \mathrm{R}$ rather than GPR55 mediated. The reasons behind the difference in

22 CP55,940 binding between the studies by Baker, Ryberg and Lauckner are not

23 immediately apparent, although Lauckner et al. suggest it may be due to a difference in

24 GPR55 transfection between the cell types used. Despite such discrepancies, however, 
1 evidence is mounting for GPR55's role in the eCB system, as demonstrated for instance

2 by Kapur and colleagues, who observed $\mathrm{AM} 251\left(\mathrm{CB}_{1} \mathrm{R}\right.$ inverse agonist $)$ and

3 SR141716A (a $\mathrm{CB}_{1} \mathrm{R}$ specific antagonist) binding to GPR55 (Kapur et al., 2009).

4 Whilst it clearly remains an 'enigmatic' receptor (Ross, 2009), research is beginning to

5 focus on possible GPR55 based therapies, with recent studies linking it to

6 neuroinflammation (Pietr et al., 2009), inflammatory and neuropathic pain (Staton et al.,

7 2008) and anorexia (Ishiguro et al., 2010).

Finally, although the identification of GPR119 in 2003 did not initially suggest

9 links to the eCB system (Fredriksson et al., 2003), later work by Overton and Soga

10 showing N-oleoylethanolamide (OEA), an AEA analogue, induced GPR119 activation

11 (Overton et al., 2006; Soga et al., 2005) suggested otherwise. Soga et al. and more

12 recently Ning et al. observed that GPR119 agonism mediates glucose-dependent insulin

13 production and release to some extent, as well as increasing intercellular cyclic

14 adenosine monophosphate (cAMP) accumulation (Ning et al., 2008; Soga et al., 2005).

15 However, despite findings that GPR119 agonism by OEA suppresses feeding in rats

16 (Rodriguez de Fonseca et al., 2001), this receptor is unlikely to be involved in centrally

17 mediated eCB feeding effects as it has been found in the gut (Overton et al., 2006;

18 Overton et al., 2008). It should nevertheless still be considered when interpreting in vivo

19 feeding study results and could represent a useful target for anti-obesity therapies

20 (Hughes, 2009).

Although, as previously mentioned, this review focuses primarily on central cannabinoid mediated feeding mechanisms, peripheral effects, such as those mediated

23 by peripheral CBRs or GPR119 add considerable complexity when interpreting in vivo

24 feeding data. This is particularly true in light of findings describing peripheral $\mathrm{CB}_{1} \mathrm{R}$ 
1 expression e.g. in the vas deferens: Pertwee et al., 1996; in the heart, blood vessels and

2 bladder: Howlett, 2002; the liver and fatty tissue: Cota et al., 2003b; Osei-Hyiaman et

3 al., 2005), and a potential modulatory role of these peripheral receptors on feeding 4 behaviour (Gomez et al., 2002). Equally, although it is thought that most of the 5 functional $\mathrm{eCB}$ effects in the brain are $\mathrm{CB}_{1} \mathrm{R}$-mediated (Piomelli, 2003), recent work 6 has suggested some functional expression of $\mathrm{CB}_{2} \mathrm{Rs}$ in the brain (Onaivi et al., 2006), 7 particularly at synapses (Morgan et al., 2009), and that these may also be involved in 8 feeding behaviours (Onaivi et al., 2008). Furthermore, CBR activation in the gut for 9 example, in terms of gut motility (Izzo et al., 2010), are also likely to have considerable 10 effects on feeding patterns. As such, it is often difficult, when interpreting in vivo 11 experimental results, to exclusively assign cannabinoid effects to either central or 12 peripheral sites of action, or to differentiate between $\mathrm{CB}_{1^{-}}$and $\mathrm{CB}_{2^{-}}$, or indeed non13 CBR-mediated effects. Moreover, ligands which produce well-characterised effects at 14 specific CBRs may also exert effects at other receptor sites, thereby creating unexpected 15 and potentially unwanted secondary effects. This is well illustrated by SR141716A 16 (Acomplia/Rimonabant), a well-known selective $\mathrm{CB}_{1} \mathrm{R}$ antagonist/inverse agonist which 17 has recently been found by Kapur et al. to agonise GPR55, and which the authors suggest may have played a part in some of the 'off-target' effects that led to its withdrawal as an anti-obesity drug (Kapur et al., 2009). There is still much to clarify about how cannabinoids produce their endogenous 21 effects, and how they might interact with each other in vivo (Ben Amar, 2006; Whalley et al., 2004). Furthermore, adding to this complexity is the eCB system's interaction with other systems, in particular the opioid system which itself has been linked to appetite regulation for some time (for an early review of opiates and appetite regulation 
1 see Morley et al., 1982). Indeed, it is now apparent that both the eCB and opioid

2 systems modulate energy balance, that both systems can modulate food intake

3 independently and that activation or suppression of both systems together can increase

4 or reduce food intake to a greater extent than modulation of either system alone (Gallate

5 et al., 1999; Kirkham et al., 2001c; Solinas et al., 2005). Whilst detailed discussion of

6 such interactions is beyond the scope of this review, they, along with the numerous

7 other complexities outlined above, are important factors to consider when looking at, or

8 indeed conducting and analysing, research on the eCB system and feeding.

9

10 


\section{Cannabinoid-mediated effects upon feeding}

2 The last decade has seen considerable advances in our understanding of eCB-mediated

3 control of feeding behaviours. Numerous anecdotal reports exist, and the 'munchies'

4 effect has become a well-accepted physiological response to $C$. sativa consumption, yet

5 few quantitative reports from this period exist (for a complete review see Kirkham et

6 al., 2001b). While the 'classical' tetrad of cannabinoid effects was defined as decreased

7 spontaneous motor activity, hypothermia, analgesia and catalepsy (Little et al., 1988), it

8 was only comparatively recently that $\Delta^{9} \mathrm{THC}$ was demonstrated to induce hyperphagia

9 (Williams et al., 1998), an effect clearly linked to $\mathrm{CB}_{1} \mathrm{R}$ rather than $\mathrm{CB}_{2} \mathrm{R}$ activation

10 (Williams et al., 2002b). Since $\mathrm{CB}_{2} \mathrm{R}$ have only recently been localised to the CNS

11 (Morgan et al., 2009), and have not been found expressed on feeding pathways, little

12 research has considered the possible effects that $\mathrm{CB}_{2} \mathrm{R}$ stimulation may have on feeding.

13 While a limited number of reports which consider $\mathrm{CB}_{2} \mathrm{R}$ effects on feeding do exist (e.g.

14 Onaivi et al., 2008), they have so far presented inconclusive evidence. Furthermore, 15 possible opioid/cannabinoid and cannabinoid/serotonergic interactions have been 16 studied, for example by Williams et al., (2002b). Williams demonstrated a functional 17 relationship between the cannabinoid and opioid systems in the control of appetite, and 18 notably rejected any serotonergic interaction: upon administration of $\Delta^{9} \mathrm{THC}$ and either 19 SR141716A, SR144528, naloxone or dexfenfluramine, Williams observed that while 20 naloxone could block $\Delta^{9}$ THC-mediated feeding increases, dexfenfluramine could not.

21 Unfortunately, a detailed description of such interactions falls beyond the scope of this 22 review, although a recent review of the effects of $\mathrm{CB}$ /opioid interactions on the 23 behavioural satiety sequence can be found in Cota et al. (2006). Given the relatively 24 recent success of treatment with $\Delta^{9} \mathrm{THC}$-based $\mathrm{CB}_{1} \mathrm{R}$ partial agonists (e.g. dronabinol or 
1 nabilone) and the remaining unmet clinical need in a range of disease states, further

2 research into pCB-mediated feeding effects is on-going and is reviewed here alongside 3 classical $\mathrm{CB}_{1} \mathrm{R}$ agonism and antagonism.

4

5 
1 Endocannabinoid agonism and its effects on feeding

$2 \Delta^{9} \mathrm{THC}$ was first shown to exert hyperphagic effects in rats in 1998 (Williams et al., 3 1998). $\Delta^{9} \mathrm{THC}(0.063-2.0 \mathrm{mg} / \mathrm{kg}$ ) administered orally (per ora; p.o.) to pre-satiated (a 4 situation in which eCB tone is reduced by the highly palatable prefeed process), adult, 5 male, Lister hooded rats, at doses $>0.5 \mathrm{mg} / \mathrm{kg}$ significantly increased chow intake 6 relative to control in the first hour following drug administration. Furthermore, no 7 significant differences in food intake between control and any $\Delta^{9} \mathrm{THC}$ doses were seen 8 over the twenty four hour period following $\Delta^{9} \mathrm{THC}$ administration. This early study

9 importantly demonstrated that very low concentrations of orally administered $\Delta^{9} \mathrm{THC}$ 10 could substantially change an animal's motivation to consume; particularly given that a 11 considerable percentage of the administered drug would have undergone first pass 12 metabolism as a result of oral administration. Intriguingly, a later study by Avraham 13 (Avraham et al., 2004) also showed that extremely low $\Delta^{8}$ THC doses (a pCB similar to $14 \Delta^{9} \mathrm{THC}$ but regarded as more stable; $0.001 \mathrm{mg} / \mathrm{kg}$; intraperitoneal; i.p.) increased feeding 15 in mice. These studies suggest that subtle modulation of the eCB system can be 16 achieved without the manifestation of the non-specific behavioural side effects 17 traditionally associated with $C$. sativa administration (Howlett et al., 2004). The drug 18 administration routes used by Williams (1998; p.o.) and Avraham (i.p.) do, however, 19 limit comparison of these results and prevent specific attribution of the effects to central 20 or peripheral sites. Exogenous AEA administration $(0.5,1.0,5.0$ and $10.0 \mathrm{mg} / \mathrm{kg}$; subcutaneous; s.c.) has also been observed to induce hyperphagia in pre-satiated rats (Williams et al., 23 1999). This study demonstrated that AEA administration significantly increased food 24 intake relative to control in the first hour of testing, in a similar fashion to $\Delta^{9} \mathrm{THC}$ 
1 (Williams et al., 1998), but unlike $\Delta^{9} \mathrm{THC}$ also induced increases in total food intake. It

2 was proposed that the observed changes in food intake pattern represented an AEA-

3 induced modification in the motivation to feed, since AEA administration caused

4 feeding to occur far sooner than under control conditions, suggesting a cannabinoid-

5 mediated modulation of normal feeding pathways. Indeed, close inspection of these data

6 shows that while vehicle-treated animals consumed only small amounts of food in the

7 first hour of testing, they consumed ten-fold more during the third hour. In slightly later

8 work, Williams et al. (2002a) used two groups of twelve, male, adult, Lister-hooded rats

9 which received $\Delta^{9} \mathrm{THC}(0.5,1.0$ or $2.0 \mathrm{mg} / \mathrm{kg}$; s.c. $)$ or AEA $(0.0,1.0,5.0$ or $10.0 \mathrm{mg} / \mathrm{kg}$;

10 s.c.) and video recordings of post-administration activity to investigate feeding

11 behaviours. It became clear that administration of both $\Delta^{9} \mathrm{THC}$ and AEA significantly

12 decrease the latency to feeding onset, increase the duration of intake and the number of

13 meals, but that only AEA increased total intake. Alongside the well-reported increases

14 in short term chow intake associated with $\Delta^{9} \mathrm{THC}$, these data suggest that $\Delta^{9} \mathrm{THC}$ and

15 AEA administration induce their effects by subtly different, and yet to be elucidated

16 pathways since two distinct changes to feeding behaviours were observed.

Like $\Delta^{9} \mathrm{THC}$, extremely low doses of AEA $(0.001 \mathrm{mg} / \mathrm{kg}$; i.p.) have also been

18 demonstrated to induce significant increases in food intake in female mice in

19 experiments which used a $40 \%$ diet restriction protocol (Hao et al., 2000). It is

20 interesting that in a situation when $\mathrm{eCB}$ tone would already be increased due to the diet

21 restriction paradigm used, further slight increases in eCB tone caused by extremely low

22 doses of AEA induced changes in feeding patterns. Furthermore, it is also interesting

23 that when Hao and colleagues administered doses of 0.7 and $4.0 \mathrm{mg} / \mathrm{kg}$ AEA (also i.p.)

24 in the same set of experiments no significant feeding effects were observed, even 
1 though, Williams (1999) demonstrated AEA effects at 1.0 and 5.0mg/kg (s.c.).

2 However, as the authors note, it is particularly difficult to compare Williams et al.

3 (1999) and Williams et al. (2002a) to Hao et al. (2000) since the experimental

4 paradigms are almost complete opposites. Indeed, Williams used a prefeed paradigm

5 followed by s.c. injections in male rats and recorded food intake over a period of six

6 hours whereas Hao used a diet restricted paradigm followed by i.p. injections in female

7 mice and recorded daily food intake over a period of one week.

AEA feeding effects were localised to $\mathrm{CB}_{1} \mathrm{R}$ sites by Williams using a presatiated paradigm in 1999 . Rats received AEA $(0.5,1.0,5.0$ and $10.0 \mathrm{mg} / \mathrm{kg} ;$ s.c. $)$ and, in a subsequent trial, AEA (1.0mg/kg; s.c.) plus SR141716A (0.1, 0.5 and 1.0mg/kg; s.c.; Williams et al., 1999). This demonstrated that AEA significantly increased food intake relative to control (in a similar fashion to $\Delta^{9} \mathrm{THC}$; Williams et al., 1998) and that the effect could be blocked by SR141716A, thus confirming a $\mathrm{CB}_{1} \mathrm{R}$-mediated mechanism of action for the observed feeding effects. In 2002 the hyperphagia induced by $\Delta^{9} \mathrm{THC}$ administration was also localised to $\mathrm{CB}_{1} \mathrm{R}$ sites (Williams et al., 2002b). Williams first induced hyperphagia by administering $\Delta^{9} \mathrm{THC}(1.0 \mathrm{mg} / \mathrm{kg}$; s.c.) and in further trials attenuated this effect with the coadministration of SR141716A $(0.1,0.5$ and $1.0 \mathrm{mg} / \mathrm{kg}$; s.c.) thereby demonstrating $\mathrm{CB}_{1} \mathrm{R}$ involvement in this effect. $\mathrm{CB}_{2} \mathrm{R}$-mediation was then discounted as coadministration of $\Delta^{9} \mathrm{THC}(1.0 \mathrm{mg} / \mathrm{kg}$; s.c.) and SR144528 (0, 0.05, 0.1, 0.5 and $1.0 \mathrm{mg} / \mathrm{kg} ;$ s.c.) failed to reduce the hyperphagia caused by $\Delta^{9} \mathrm{THC}$ administration.

Although Williams et al. (1999) localised AEA-mediated effects on feeding to $\mathrm{CB}_{1} \mathrm{R}$, an effect which one can attribute to $\mathrm{CNS}$ receptors, evidence which links peripheral mechanisms to these effects also exists. Gomez and colleagues (Gomez et al., 
1 2002) demonstrated that intracerebroventricular (i.c.v.) AEA administration $(10.0 \mu \mathrm{g} / \mathrm{kg})$

2 and WIN55,212 $(10.0 \mu \mathrm{g} / \mathrm{kg})$ increased food intake, but that i.c.v. SR141716A

3 administration $(0.1,0.4,2.0$ or $10.0 \mu \mathrm{g} / \mathrm{kg})$ did not reduce feeding. In contrast, whilst i.p.

4 administration of AEA (0.1, 1.0 and $10.0 \mathrm{mg} / \mathrm{kg})$ and WIN55,212 (0.4, 2.0 and

$510.0 \mathrm{mg} / \mathrm{kg})$ similarly increased food intake, i.p. administration of SR141716A $(0.3,1.0$

6 and $3.0 \mathrm{mg} / \mathrm{kg}$ ) reduced feeding. Furthermore, the authors demonstrated that the changes

7 in feeding patterns they observed were unaffected by a $\mathrm{CB}_{2} \mathrm{R}$ antagonist (SR144528;

$83.0 \mathrm{mg} / \mathrm{kg}$; i.p.), principally rejecting the hypothesis that these peripheral effects were in

9 fact $\mathrm{CB}_{2} \mathrm{R}$ - as opposed to $\mathrm{CB}_{1} \mathrm{R}$-mediated. SR141716A's failure to reduce feeding after

10 i.c.v. but not i.p. administration led Gomez to suggest that $\mathrm{CB}_{1}$ Rs must be present in the

11 periphery and that these peripheral $\mathrm{CB}_{1} \mathrm{Rs}$ can affect feeding. Gomez supports this

12 assertion by showing that intestinal AEA levels increase after food deprivation,

13 suggesting that intestinal endocannabinergic tone plays a role in energy balance.

14 However, the experimental paradigm used by Gomez did not account for the

15 concentrations of SR141716A, AEA and WIN55,212 that would be present in the CNS

16 following i.p. injection or for the considerably different dose ranges used. As such,

17 while this evidence is suggestive of a peripheral $\mathrm{CB}_{1} \mathrm{R}$-mediated role in energy balance,

18 further experiments are needed to confirm this.

19 It has been well described that upon administration of an exogenous cannabinoid

20 agonist endocannabinergic tone will be increased and that alterations to feeding patterns

21 can then be observed. Furthermore, it has been demonstrated that naturally occurring

22 eCB concentrations fluctuate in various feeding states. Alongside evidence gathered

23 using exogenous cannabinoid administration to affect feeding patterns, this elegantly

24 demonstrates a link between how the natural eCB system modulates feeding patterns 
1 and how artificial alterations to its state modulate the same patterns. AEA and 2-AG

2 levels in the rat limbic forebrain, hypothalamus and cerebellum were quantified in three

3 feeding states; fasted, feeding and satiated (Kirkham et al., 2002). Four groups of 4 between eight and ten male rats were either: 1) given ad libitum access to food and 5 sacrificed during a period of low spontaneous feeding; 2) fed with a wet mash for 15 6 minutes and then sacrificed during feed consumption; 3) fed with a wet mash and 7 sacrificed once they stopped eating or 4) given a $20 \%$ maintenance diet for $24 \mathrm{hrs}$ and 8 sacrificed at the start of their red light cycle the following day. Brain tissue was then 9 extracted and AEA and 2-AG levels were assessed in the limbic forebrain, 10 hypothalamus and cerebellum. AEA and 2-AG levels were significantly elevated by 11 food deprivation in the limbic forebrain while 2-AG concentration was significantly 12 reduced in the hypothalamus during the feeding state but significantly increased during 13 the deprived state. Since 2-AG levels were increased in the limbic forebrain and 14 hypothalamus, and AEA levels were significantly increased in the limbic forebrain, it 15 appears that elevated eCB levels in important reward-related brain areas during food 16 deprivation play a role in motivating animals towards food. The reduction of 2-AG 17 levels in the hypothalamus during feeding suggests that 2-AG is actively suppressed 18 during feeding to facilitate satiation. Such data suggest subtly differing roles for AEA 19 and 2-AG in feeding cycles.

20 Further experiments published in the same manuscript revealed that 2-AG (i.c.v. 21 into the nucleus accumbens at 0.5 and $2.0 \mu \mathrm{g}$ ) could significantly increase food intake 22 over a one hour period while coadministration of SR141716A $(0.5 \mathrm{mg} / \mathrm{kg}$; s.c. plus $230.5 \mu \mathrm{g} 2-\mathrm{AG}$; i.c.v.) could almost fully attenuate this effect, thereby demonstrating $\mathrm{CB}_{1} \mathrm{R}$ 24 mediation. The increases in food intake seen in Kirkham et al. (2002) are comparable to 
1 the similar studies performed by the same group following $\Delta^{9} \mathrm{THC}$ administration

2 (Williams et al., 2002b; Williams et al., 1998), however are considerably different from

3 a feeding study which administered AEA (Williams et al., 1999). Indeed, AEA

$4 \quad(1.0 \mathrm{mg} / \mathrm{kg} ;$ s.c.) effects were observed over four hours and during the first hour

5 significantly increased intake by a factor of approximately two, as well as significantly

6 elevating food intake over the entire four hour period. In contrast, 2-AG (0.5 and

$71.0 \mu \mathrm{g} / \mathrm{kg}$; i.c.v.) significantly increased food intake by factors of nine and seven,

8 respectively, over a one hour period. However, it is important to note that in this

9 instance 2-AG administration was i.c.v. and AEA administration was s.c., and it is

10 possible that AEA-mediated feeding increases would have been larger had

11 administration been i.c.v. Given the strong anatomical connections between the nucleus

12 accumbens shell and the hypothalamus (Stratford et al., 1999) and the importance of the

13 hypothalamus in the integration of feeding pathways (Maccarrone et al., 2010) these

14 data represent a demonstration that modulation of this pathway can have profound

15 feeding effects.

16 As considerable differences in eCB levels in the limbic forebrain were seen

17 during various feeding states in (Kirkham et al., 2002) and because the limbic forebrain

18 is traditionally associated with reward processing, possible interactions between the

19 eCB and opioid systems were then considered by Williams and Kirkham (Williams et

20 al., 2002b). It was demonstrated that $\Delta^{9}$ THC-induced hyperphagia could be attenuated

21 by the opioid antagonist naloxone. This proves a link between opioid food reward

22 processing and the eCB system. These experiments are also exciting in terms of putative

23 anti-obesity treatments. Indeed, it has been reported that in obese humans, eCB levels

24 are elevated by up to 52\% (Engeli et al., 2005); as such experiments which artificially 
1 elevate eCB activity using food-restriction paradigms are particularly valuable since

2 they more accurately model the human obese condition. Moreover, since in both the

3 food deprived and obese states eCB levels are increased, this further supports the theory

4 that eCB dysfunction plays an important part in human obesity. Further studies which

5 directly compared AEA and 2-AG-induced feeding effects (both centrally and

6 peripherally administered) would be extremely useful. It would be equally compelling

7 for further work to consider fully the putative effects of peripheral cannabinoid

8 receptors on feeding behaviours, for example in terms of gut motility.

Given the previously discussed alterations to $\mathrm{eCB}$ concentrations in the limbic

10 forebrain, an area traditionally associated with reward processing and well documented

11 opioid/cannabinoid interactions, it is clear that the changes to behavioural patterns

12 observed during cannabinoid administration are due to changes in reward levels.

13 Therefore, cannabinoid agonist effects on the consumption of different types of

14 rewarding ingesta, such as sweet versus fatty foods, was addressed in a study by Koch

15 (2001). Here, $\Delta^{9} \mathrm{THC}(0.0,0.5,1.0$ and $2.5 \mathrm{mg} / \mathrm{kg}$; i.p.) was administered to rats

16 receiving either control (chow), high fat (HF) or high fat plus sugar (HFS) diets and

17 food intake was recorded over 24 hours post-injection. After the first hour, 0.5 and

$181.0 \mathrm{mg} / \mathrm{kg} \Delta^{9} \mathrm{THC}$ significantly increased food intake versus control within the HF diet

19 group only, while doses of $2.5 \mathrm{mg} / \mathrm{kg}$ had no significant effects on intake in any group.

20 However, overall food intake during the first hour was significantly greater in the HF

21 group than in either the control chow or HFS groups. During the second hour of testing,

22 the 0.5 and $1.0 \mathrm{mg} / \mathrm{kg} \Delta^{9} \mathrm{THC}$ doses significantly increased intake versus control in all

23 three groups with $1.0 \mathrm{mg} / \mathrm{kg}$ causing the largest increases. This dose also induced a

24 significantly greater intake increase in the HF (but not in the HFS) than in the control 
1 chow group, although overall food intake across all doses was significantly greater in

2 both the HF and HFS groups, relative to the control chow group. Finally in the fourth

3 hour, unlike previous feeding studies employing $\Delta^{9} \mathrm{THC}$ which showed effects lasting

4 fewer than four hours, $\Delta^{9} \mathrm{THC}$ doses of $1.0 \mathrm{mg} / \mathrm{kg}$ still induced significant increases in

5 consumption compared to vehicle in the HF and HFS diet groups.

The increases in intake seen at lower dose levels by Koch appear comparable

7 (though reduced) to those previously reported (Williams et al., 1998) and support a

8 cannabinoid-mediated stimulation of intake (Williams et al., 1999; Williams et al.,

9 1998), although the non-significant effects of $2.5 \mathrm{mg} / \mathrm{kg} \Delta^{9} \mathrm{THC}$ remain unexplained,

10 particularly as no changes to motor coordination or the appearance of tetrad effects were

11 reported for this dose. Therefore, it is clear from these results that eCB system

12 stimulation induces greater increases in the intake of highly fatty food-types (HF) than

13 other, less calorific or more palatable, diets (HFS). Previous work by Arnone et al.

14 (1997) and Simiand et al. (1998) (this work is fully discussed in 'Endocannabinoid

15 antagonists and their effects on feeding') would suggest that the HFS intake should also

16 have been increased by $\Delta^{9} \mathrm{THC}$ administration. Indeed, $\Delta^{9} \mathrm{THC}$ administration induced

17 similar intake increases in the HFS and HF diet groups but only after the fourth and

18 twenty-fourth hours of testing. These data could suggest that the eCB system is

19 involved more strongly in increasing the motivation to consume high fat foods and that

20 this effect manifests more quickly than eCB increases due to other 'bland' food types.

21 From the perspective of evolution, an increased motivation to consume high fat foods is

22 obvious and as such it is reasonable to suggest from this data that the eCB system is

23 intimately involved in this process. 
1

2 palatability, Higgs et al. (2003) tested the effects of various cannabinoid receptor

3 ligands on consumption of a $10 \%$ sucrose solution in rats. In this test $\Delta^{9} \mathrm{THC}$ or AEA

$4(0.5,1.0$ or $3.0 \mathrm{mg} / \mathrm{kg}$ in both cases; i.p.) but not $2-\mathrm{AG}(0.2,0.5$ and $2.0 \mathrm{mg} / \mathrm{kg}$; i.p. $)$

5 significantly increased sucrose solution consumption. By analysing lick patterns using

6 the mathematical model of ingestive control proposed by Davis et al. (1977), this effect

7 was ascribed to a cannabinoid-induced increase in perceived palatability. The lack of

8 significant 2-AG-induced effect is surprising, since both 2-AG and AEA are partial

9 agonists at $\mathrm{CB}_{1} \mathrm{R}$ sites (although it has been suggested that 2-AG is the main ligand

10 associated with $\mathrm{CB}_{2} \mathrm{R}$ sites; Sugiura et al., 1999; Sugiura et al., 2000), and because of

11 the significant effects observed by Kirkham et al., (2002). Higgs suggests that different

12 speeds at which the exogenous and endogenous ligands act, coupled with the probable

13 lack of 2-AG brain penetration (due to the route of administration), can explain the

14 reduced effects of AEA compared to $\Delta^{9} \mathrm{THC}$ and could, to some extent, shed light on

15 the limited effects of 2-AG. Administration of SR141716A alone was also tested (0.5,

161.0 and $3.0 \mathrm{mg} / \mathrm{kg}$; i.p.) by Higgs, and found to elicit a dose-dependent decrease in

17 consumption, thus linking the observed effects to modulation of endogenous $\mathrm{CB}_{1} \mathrm{R}$

18 activation. Yet, it could be argued that the dose-dependent decreases in consumption

19 induced by SR141716A seen here were caused by a reduction in eCB tone of which 2-

20 AG plays a part, and as such it remains impossible to discount any effects of 2-AG

21 acting at $\mathrm{CB}_{2} \mathrm{R}$ sites on this process. This finding demonstrates that the eCB system

22 must have an active effect upon appetite and feeding since $\mathrm{CB}_{1} \mathrm{R}$ blockade alone,

23 without co-administration of a cannabinoid agonist (c.f. Gallate et al., 1999; Williams et

24 al., 1999), significantly reduces consumption. Considering the works of Koch (2001), 
1 Gallate et al. (1999) and Williams et al. (1999) it can be suggested that eCB system

2 stimulation upregulates the palatability of high calorie, low palatability foods and

3 conversely, reducing endocannabinergic tone diminishes perceived palatability. This

4 could explain why in Koch's work the HF diet intake was increased above HFS diet as

5 it was both palatable and calorie-rich.

6

7 AG to both wild type and $\mathrm{CB}_{1} \mathrm{R}$ knock-out mice. They observed that AEA and 2-AG

8 preferentially increased taste responses to sweet rather than salty, sour, bitter or umami

9 (a Japanese term for a meaty or savoury taste) flavours in the chorda tympani nerve,

10 fungiform taste buds and during a short-term lick response test. Furthermore, they did

11 not observe this effect in their knock-out mice, hence linking this effect to $\mathrm{CB}_{1} \mathrm{R}$. Given

12 their i.p. route of administration, the authors have suggested a peripheral effect,

13 alongside the well described central effect, of eCBs on taste. In comparison with the work of Higgs et al (2003) who found 2-AG to have little effect on palatability in a progressive lick-based paradigm, and considering that both studies used i.p. administration and observed peripheral taste responses, it is not immediately apparent why different eCBs are identified as the principal modulators of taste.

In earlier taste reactivity studies, Gallate et al. (1999) presented rats with various concentrations of 'beer' $(<0.5 \%, 2.7 \%$ or $4.0 \%$ ethanol solutions $)$ or an $8.6 \%$ sugar solution, and their motivation to consume these substances was measured using a lickbased progressive ratio paradigm. In order to assess $\mathrm{CB}_{1} \mathrm{R}$ involvement, animals were treated with either vehicle, the $\mathrm{CB}_{1} \mathrm{R}$ agonist $\mathrm{CP} 55,940(10.0,30.0$ or $50.0 \mu \mathrm{g} / \mathrm{kg}$; i.p.),

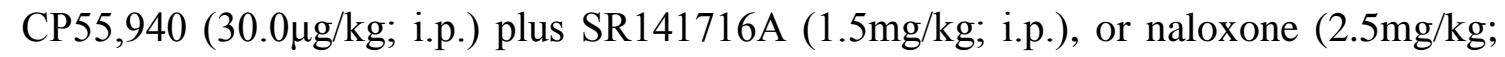
i.p.) plus $\mathrm{CP} 55,940(30.0 \mu \mathrm{g} / \mathrm{kg}$; i.p.). This drug regime therefore also examined 
1 potential interactions between the cannabinoid and opioid systems. In agreement with

2 previous research, CP55,940-treated animals exhibited a significant trend whereby

3 increasing dose led to increases in both beer and sucrose solution consumption.

4 SR141716A-induced $\mathrm{CB}_{1} \mathrm{R}$ blockade during CP55,940 treatment attenuated this effect,

5 reducing beer solution intake to levels that did not differ from vehicle treatments.

6 Furthermore, CP55,940 plus naloxone administration significantly reduced beer intake

7 to approximately $50 \%$ of vehicle intake, confirming a strong interaction between $\mathrm{CB}_{1}$

8 and opioid receptors in the control of alcohol consumption. This study demonstrated

9 that $\mathrm{CB}_{1} \mathrm{R}$ activation could induce significant increases in palatable solution intake

10 when compared to vehicle-treatments, and that this effect was attenuated by $\mathrm{CB}_{1} \mathrm{R}$

11 antagonists; further supporting the theory of $\mathrm{CB}_{1} \mathrm{R}$ involvement in perceived 12 palatability.

In 2005 and 2007 Jarrett et al. (Jarrett et al., 2005; Jarrett et al., 2007)

14 demonstrated that the eCB system mediated the perceived palatability of sweet and

15 bitter tastes. In trials using adult, male Sprague-Dawley rats, $\Delta^{9}$ THC $(0.5 \mathrm{mg} / \mathrm{kg}$; i.p.),

$16 \Delta^{9} \mathrm{THC}(0.5 \mathrm{mg} / \mathrm{kg}$; i.p.) plus SR141716A (2.5mg/kg; i.p.) or AM251 (1.0mg/kg; i.p.), or

17 AM251 (1.0mg/kg; i.p.) alone were administered via intraoral cannulae and the

18 orofacial reactions to intraoral administration of either sucrose (2, 10 and $32 \%$ ), or

19 quinine $(0.01$ or $0.05 \%)$ solutions were recorded. $\Delta^{9} \mathrm{THC}$ increased the perceived

20 palatability of the sucrose solution, an effect attenuated in animals treated with $\Delta^{9} \mathrm{THC}$

21 plus SR141716A (Jarrett et al., 2005). In the later study, $\Delta^{9} \mathrm{THC}$ reduced aversiveness

22 to $0.05 \%$ quinine solution, an effect that was blocked by coadministration of AM251

23 (Jarrett et al., 2007). The authors suggest that their results indicate that increases in

$24 \mathrm{CB}_{1} \mathrm{R}$ responsiveness could be involved in a general upregulation of the ingesta 
1 palatability. In further experiments during the same two studies, Jarrett and colleagues

2 also demonstrated that SR141716A administration alone does not reduce perceived

3 palatability (Jarrett et al., 2005) but AM251 administration enhances aversiveness

4 (Jarrett et al., 2007). This may suggest that the increased palatability of sweet food can

5 activate the $\mathrm{eCB}$ system and upregulate $\mathrm{eCB}$ tone. However, in the case of bitter tasting

6 food, when eCB tone would not be increased by the low palatability of the food, $\mathrm{CB}_{1} \mathrm{R}$

7 antagonism can then reduce the perceived palatability of the food further.

Further supporting this palatability hypothesis, it has recently been demonstrated

9 that, under a reinforced learning paradigm which included food type (normal lab chow,

10 chocolate pellets or fat-enriched pellets) selection as an experimental variable, mice will

11 select the sugar rich, highly-palatable food type or fatty foods over standard food after

$12 \Delta^{9} \mathrm{THC}(1.0 \mathrm{mg} / \mathrm{kg}$; i.p.) administration (Barbano et al., 2009). Since, the chocolate-

13 enhanced pellets used in this study had the same calorific content as the standard food

14 pellets also employed while the fat enriched pellets contained approximately $66 \%$ more

15 calories per gram but no added chocolate, it can be observed that $\Delta^{9} \mathrm{THC}$ administration

16 increased the palatability of fatty foods to a level comparable to that of sweet foods.

17 The conclusion that the eCB system exerts a level of control over palatability

18 reward is well supported. It has been shown that increased eCB tone increases the

19 palatability of sweet liquids (Gallate et al., 1999; Higgs et al., 2003), bland fatty foods

20 (Koch, 2001) or even aversive, bitter liquids (Jarrett et al., 2005; Jarrett et al., 2007).

21 Indeed, eCB levels change naturally reflecting the current feeding state, and it is this

22 basal tone that can be altered with the application of $\mathrm{CB}_{1} \mathrm{R}$ ligands. Furthermore, the

23 meal pattern changes induced by stimulation of the eCB system are also well

24 understood. $\triangle^{9} \mathrm{THC}$ administration has been demonstrated to reduce the latency to 
1 feeding onset in periods of reduced endocannabinergic tone and has also been shown to

2 increase meal sizes. If we consider appetitive behaviours as those that regulate the

3 latencies to meal onset and consummatory behaviours as those that regulate the size of

4 any given meal, what becomes clear from these data is that modulation of the eCB

5 system can affect consummatory and/or appetitive behaviours and that these different

6 behavioural changes can be manipulated individually. For example, in the work of

7 Williams et al. (2002a), a distinct separation was seen between the AEA and $\Delta^{9}$ THC

8 groups in terms of feeding behaviour. In this instance, AEA administration produced

9 effects comparable to $\Delta^{9} \mathrm{THC}$ : AEA significantly reduced the latency to feeding onset,

10 whilst also increasing the number of eating bouts. AEA administration also increased

11 meal duration and the duration of the longest bout versus control conditions. However,

12 unlike $\Delta^{9}$ THC, AEA induced significant increases in total intake over the test period.

13 Given these data it can be clearly seen that the changes to feeding patterns (either in

14 gross terms or in terms of palatability levels) are due to changes to reward processing.

15 Indeed, the decreased latency to feeding onset and the increased size and length of

16 meals thereafter coupled with increased lick responses can all be linked to increased

17 reward. 
$1 \quad$ Endocannabinoid antagonism and its effect on feeding

2 Alongside the well documented hyperphagic effects of $\Delta^{9} \mathrm{THC}$ administration there is

3 comprehensive complimentary evidence which details the effects of reducing eCB tone

4 on feeding behaviours. Indeed the use of $\mathrm{CB}_{1} \mathrm{R}$ antagonist-based studies represents an

5 elegant way to study the effects of basal eCB tone on physiological feeding

6 mechanisms. This is particularly true as many CBR antagonists are highly selective. In

71997 Arnone (Arnone et al., 1997) and colleagues performed a comprehensive set of

8 experiments which revealed the changes to feeding behaviours induced by $C_{1} R$

9 blockade by the administration of SR141716A $(0.0,0.1,0.3,1.0$ or $3.0 \mathrm{mg} / \mathrm{kg}$ : i.p.). In

10 experiments which studied either intake of sucrose pellets, intake of a $5 \%$ sucrose

11 solution or a $10 \%$ ethanol solution, Arnone demonstrated that eCB tone plays an

12 important role in the perceived appetitive values of both alcohol and sugar. Firstly,

13 Arnone and colleagues measured the weight of food consumed in 30min open field tests

14 where food-restricted male, Wistar rats (a situation in which one would expect eCB tone

15 to be increased by the food restriction (Kirkham et al., 2002)) had access to either

16 sucrose pellets and standard lab chow or standard lab chow alone after SR141716A

17 administration. The quantity of sucrose pellets consumed by rats was reduced from

$183.1 \pm 0.4 \mathrm{~g}$ under control conditions to $1.0 \pm 0.4 \mathrm{~g}$ after the $3.0 \mathrm{mg} / \mathrm{kg}$ SR141716A dose in a

19 dose-dependent fashion; furthermore, the two highest doses of SR141716A induced

20 significant reductions when compared to control intakes. Standard chow intake was

21 unaffected. However, when Arnone repeatedly administered 3.0mg/kg SR141716A in

22 mice with a predisposition to alcohol consumption over four, six hour test periods in

23 one day, SR141716A induced a suppression of ethanol intake. Secondly, rats (male,

24 Sprague-Dawley) were given access to a 5\% sucrose solution for a period of four hours 
1 without access to food and water. As a control experiment another group of rats was

2 given access to water for the same test period. Sucrose solution intake was significantly

3 reduced by the two highest doses of SR141716A and a significant dose-dependent

4 reduction in sucrose solution intake was apparent. Water intake was unaffected by

5 SR141716A administration at any dose. Thirdly, Arnone tested the effect SR141716A

6 had on ethanol consumption in male C57BL6 mice; once again administration of either

71.0 or $3.0 \mathrm{mg} / \mathrm{kg}$ SR141716A induced significant reductions in consumption versus

8 control-treatment and a significant dose-dependent effect was apparent for the entire

9 dose range. Water-only tests were used as a control, as per the 5\% sucrose solution test,

10 and no effect of SR141716A was apparent. These three experiments demonstrate that

11 the eCB system plays an active role in the control of the appetitive value of sweet and

12 alcoholic ingesta. Indeed, such experiments prove that the eCB system must have a

13 constantly active basal tone as antagonists applied to an inactive system would induce

14 no behavioural changes alone. Furthermore, given the selectivity of SR141716A we can

15 be confident that this effect is localised to $\mathrm{CB}_{1} \mathrm{R}$ sites.

16 Reductions in eCB tone induced by the administration of SR141716A (0.0, 1.0

17 and 3.0mg/kg; p.o.) were extended to marmosets in 1998 by Simiand (Simiand et al.,

18 1998). Marmosets were habituated to a high-sugar mash (HSM; 33\% sugar, 67\% milk

19 and cereal) and after habituation administered SR141716A twice a week; their food

20 (either HSM or standard diet) intake was then observed for a period of six hours.

21 Administration of the $3.0 \mathrm{mg} / \mathrm{kg}$ dose induced significant reductions in HSM intake

22 versus control-treatments after one, three and six hours while the $1.0 \mathrm{mg} / \mathrm{kg}$ dose only

23 reduced HSM intake versus control-treatments during hours one and three. Notably

24 standard diet intake was unaffected by SR141716A administration with the exception of 
1 a significant increase in intake seen during hour six. These data demonstrate that

2 SR141716A can preferentially reduce intake of sweet, highly palatable food, versus

3 bland food. This suggests that $\mathrm{eCB}$ tone is responsible for increasing the appetitive

4 values of high-sugar foods under normal physiological conditions. Indeed, as previously

5 discussed, such work has been supported by later experiments which showed

6 SR141716A administration could reduce the reward associated with sucrose solutions

7 (Higgs et al., 2003). Since Arnone et al. (1997) and Simiand et al. (1998), together,

8 used two strains of rats, one strain of mouse and one type of primate and observed

9 similar results, it can be suggested that the effects of the eCB system are similar across

10 species. However, the work of Arnone and Simiand did not consider a high fat diet

11 alternative to the high-sugar foods they used, and they only antagonised the eCB system

12 over a shorter period of time. It is worthwhile comparing the works of Arnone and

13 Simiand to that of Williams and colleagues. Indeed, while Williams observed $\mathrm{CB}_{1} \mathrm{R}$

14 stimulation to increase feeding, and that this effect could be blocked by

15 coadministration of SR141716A, Arnone and Simiand demonstrated a basal

16 endocannabinergic tone which when blocked with SR141716A alone could reduce

17 feeding. Furthermore, as discussed, the eCB system has been demonstrated to alter its

18 activity level dependent on feeding state (e.g. deprived of food versus eating; Kirkham

19 et al., 2002). Taken together, these studies demonstrate that eCB tone is a powerful

20 effector of perceived hunger and that feeding reduces endocannabinergic tone in the

21 same way as blocking $\mathrm{CB}_{1} \mathrm{R}$ sites in the CNS.

$\Delta^{9} \mathrm{THC}$-induced effects on high fat versus high sugar foods were well described by Koch in 2001. However, only recently were antagonist studies used to facilitate the understanding of the role of $\mathrm{CB}_{1} \mathrm{R}$ alone in the selection and consumption of highly 
1 fatty or sweet foods. In 2007, a study by Thornton-Jones et al. (2007) examined the

2 effects of SR141716A-induced $\mathrm{CB}_{1} \mathrm{R}$ blockade on consumption of sweet (10\% sucrose)

3 or fatty (10\% intralipid) solutions and analysed the lick-based response in a way similar

4 to Higgs et al. (2003). Appealingly, this paradigm also compared the hypophagic

5 SR141716A effects with those induced by behavioural manipulations designed to

6 reduce either motivation to feed (pre-feeding) or food palatability (addition of quinine to

7 the intralipid solution and reduction of sucrose concentration to 5\%) which, combined

8 with the lick-based microstructure analysis, allowed for more detailed interpretation of

9 the results. Supporting previous findings, this study demonstrated that SR141716A

10 treatment reduced both sucrose and intralipid solution intake, and microstructure

11 analysis revealed that these reductions were due to decreased perceived palatability of

12 ingesta. However, whilst these significant reductions were induced by both $1.0 \mathrm{mg} / \mathrm{kg}$

13 and $3.0 \mathrm{mg} / \mathrm{kg}$ SR141716A for the intralipid solution, only $3.0 \mathrm{mg} / \mathrm{kg}$ SR141716A

14 significantly reduced sucrose solution consumption. Furthermore, reduced lick duration

15 of intralipid solution observed after drug administration led the authors to suggest that

16 the SR141716A-induced reduction in consumption of this solution was a result of a

17 decrease in motivation to feed, as well as an effect on perceived palatability. In contrast,

18 reductions in sucrose solution intake were less pronounced than those seen for the

19 intralipid solution, suggesting that eCBS may be more strongly implicated in

20 consumption of highly calorific than sweet, palatable food-types. Taken alone, this work

21 suggests that the eCB system can play its role in energy homeostasis via modulation of

22 the motivation to consume fatty foods specifically; this long term effect may be due to

23 changes in meal patterning over the shorter term, particularly with respect to the control

24 of fat intake. Indeed, the work of Thornton-Jones further supports the findings of 
1 Arnone et al. (1997), Simiand et al. (1998) and Koch (2001), as previously discussed,

2 and strengthens the link between $\mathrm{CB}_{1} \mathrm{R}$ activation and the control of feeding. also addressed these issues, and provided further support for eCB system involvement

5 in the specific consumption of highly fatty and/or sweet foods. A 'dessert protocol' was

6 employed, whereby rats were given ad libitum access to a wet mash diet made from

7 standard laboratory chow in addition to simultaneous but time limited access to a

8 'dessert' diet high in fat and sugar. Vitally, this methodology gave rats a choice between

9 two different diets, allowing within-group analysis of diet selection. eCB system

10 involvement in the consumption of these two different food-types was assessed by

11 administration of either of the $\mathrm{CB}_{1} \mathrm{R}$ antagonists, SR141716A (1.0mg/kg; i.p.) or

$12 \operatorname{AM} 251(0.3,1.0$ or $3.0 \mathrm{mg} / \mathrm{kg}$; i.p.) $30 \mathrm{~min}$ prior to dessert access. Both compounds

13 significantly reduced caloric intake over a 24 hour period, but this effect was due to a

14 significant decrease in the consumption of the high fat and sugar diet only, with no

15 effect on the consumption of the standard chow. When considered alongside Arnone et 16 al. (1997), Koch (2001), Simiand et al. (1998) and Thornton-Jones et al. (2007), these

17 findings suggest that $\mathrm{CB}_{1} \mathrm{R}$-mediation of intake not only modulates intake of fatty food 18 more that sugary food, but does so in a preferential fashion. Unfortunately, although

19 Mathes et al., in the earlier stages of this study, compared the consumption of the high

20 fat and sugar diet with another diet high in sugar only, the effects of $\mathrm{CB}_{1} \mathrm{R}$ blockade on 21 this sugar-only diet were not examined.

While the use of the previously discussed antagonists has been shown to reduce

23 feeding in a number of models, there is considerable on-going research looking for 24 novel compounds which perform similar actions. Such research is performed to further 
1 our understanding of the eCB system and its ligands, whilst also searching for new anti-

2 obesity drugs (for examples please see PSNCBAM-1, Horswill et al., 2007; AM4113,

3 Sink et al., 2007; O-2050, Gardner et al., 2006; MK55-96, Yan et al., 2010; and MK-

4 0364, Fong et al., 2007). While, O-2050 was found to induce significant reductions in

5 motor coordination, which may have been the cause for its effects on feeding

6 behaviours, PSNCBAM-1, AM4113 and MK-5596 have been demonstrated to reduce

7 short term intake and reduce body weight in animal models without apparent side

8 effects. Further work using these novel agents would benefit from the inclusion of meal

9 patterning analysis as this would allow the study of appetitive and/or consummatory

10 behaviours, as well as effects on perceived palatability; such an analysis may shed more

11 light on eCB mediation of feeding behaviours.

12 


\section{$1 \quad$ Non- $\Delta^{9}$ THC phytocannabinoid effects on feeding}

2 Very recently it has been suggested that non- $\Delta^{9}$ THC pCBs can also modulate rodent

3 feeding patterns (Farrimond et al., 2010a; Farrimond et al., 2010b) and induce different

4 changes than $\Delta^{9} \mathrm{THC}$, without any apparent non-specific behavioural effects. Before

52009 there had been a limited number of studies which demonstrated non- $\Delta^{9} \mathrm{THC}$ pCB-

6 mediated feeding effects. Unfortunately these studies were either unrepeated or

7 contradictory. Sofia and Knobloch (1976) reported that the $\mathrm{CB}_{1} \mathrm{R}$ agonist $\mathrm{CBN}$ reduced

8 intake in rats, an effect yet to be repeated, and that CBD also reduced feeding in rats.

9 However, Wiley et al., (2005) reported that CBD administration had no effect on food

10 intake in mice, a result repeated by Riedel (2009) who observed only a small, non-

11 significant reduction in food intake and weight gain, also in mice. It should be noted

12 that the dose ranges used by Sofia, Knobloch and Wiley are considerably higher than

13 those used by Farrimond and colleagues and, given the well described bi-phasic dose

14 effects of $\mathrm{CB}_{1} \mathrm{R}$ activation (Glick et al., 1972) on feeding, this may explain the

15 differences in observed effect patterns. Work in our laboratory has demonstrated that a

16 range of pCBs may have significant effects on feeding patterns. Thirty-six pre-satiated,

17 male, Lister-hooded rats received a purified, $C$. sativa-derived $\Delta^{9} \mathrm{THC}$ (hereafter

18 purified $\Delta^{9} \mathrm{THC}$ ), a synthetic $\Delta^{9} \mathrm{THC}$ and a high- $\Delta^{9} \mathrm{THC}$ standardised botanical drug

19 substance (BDS), similar in composition to that used in Sativex and containing a typical

20 array of non- $\Delta^{9} \mathrm{THC}$ pCBs (high- $\Delta^{9} \mathrm{THC}$ BDS; all treatments were dose matched for

$21 \Delta^{9}$ THC content; 0.00, 0.34, 0.67, 1.34 and 2.68mg/kg; p.o.; Farrimond et al., 2010a).

22 Synthetic and purified $\Delta^{9} \mathrm{THC}$ administration induced classical $\Delta^{9} \mathrm{THC}$ hyperphagia in

23 this study: the latency to the first meal was reduced and both the first hour intake and

24 first meal duration were increased versus vehicle treatments. Intriguingly, the effects of 
1 the high- $\Delta^{9}$ THC BDS administered showed significantly reduced hyperphagia in

2 comparison. These results suggested that the combination of pCBs (and, potentially,

3 non-cannabinoid components) in the high- $\Delta^{9}$ THC BDS attenuated the hyperphagic

4 effects of $\Delta^{9} \mathrm{THC}$. Given the constituents of the high- $\Delta^{9} \mathrm{THC}$ BDS, $\left(\Delta^{9} \mathrm{THC} ; 67.0 \%\right.$,

5 Cannabigerol (CBG); 1.7\%, Cannabichromene (CBC); 1.6\%, CBN; 1.5\%, $\Delta^{9} \mathrm{THCV}$;

$6 \quad 0.9 \%, \Delta^{9}$ tetrahydrocannbinolic acid $\left(\Delta^{9} \mathrm{THCA}\right) ; 0.3 \%, \mathrm{CBD} ; 0.3 \%$ and Cannabitriol

$7(\mathrm{CBO}) ; 0.2 \%)$ it is possible that the pCBs present could have affected feeding

8 synergistically, or that at least one pCB modulated the $\Delta^{9}$ THC-induced hyperphagia.

9 Indeed, the high- $\Delta^{9}$ THC BDS used in Farrimond et al., (2010a) contained known $\mathrm{CB}_{1} \mathrm{R}$

10 antagonists ( $\Delta^{9} \mathrm{THCV}$, Dennis et al., 2008; Ma et al., 2008; Thomas et al., 2005) in

11 addition to modulators of $\mathrm{Ca}^{2+}$ homeostasis (CBD; Ryan et al., 2009) and CBN (Rao et

12 al., 2006); which could modulate eCB levels. However, these results do not preclude the

13 possibility that non-cannabinoid material also present in the high- $\Delta^{9}$ THC BDS also

14 contributed to the observed behavioural effects.

15 Consistent with these results we have also demonstrated that non- $\Delta^{9}$ THC pCBs

16 can affect feeding when co-administered with sub-effective concentrations of $\Delta^{9} \mathrm{THC}$

17 (Farrimond et al., 2010b; please also see Riedel et al., 2009 for non- $\Delta^{9}$ THC pCB-

18 induced hypophagia fully discussed below). Ten, pre-satiated, adult, male, Lister-

19 hooded rats received a low $-\Delta^{9}$ THC standardised BDS (low $-\Delta^{9}$ THC BDS; 0.0, 0.5, 1.0,

202.0 and $4.0 \mathrm{mg} / \mathrm{kg}$; p.o.) containing only $6.9 \% \Delta^{9} \mathrm{THC}$, alongside $14.2 \%$ other pCBs.

21 Conversely, at these concentrations, rather than having no effect on feeding (as it might

22 be expected, given the use of a prefeed paradigm with an extremely low dose of $\Delta^{9} \mathrm{THC}$

23 and $\mathrm{pCBs}$ that have previously been shown to reduce $\Delta^{9}$ THC-mediated hyperphagia),

24 the low $-\Delta^{9}$ THC BDS significantly increased chow intake during the first hour, by 
1 significantly reducing the latency to the first contact with food for the highest doses

2 versus vehicle-treatments. These reductions in meal one latency mirror those previously

3 demonstrated for considerably higher concentrations of pure $\Delta^{9} \mathrm{THC}$ (Farrimond et al.,

4 2010a; Williams et al., 1998). Furthermore, while the latency to the first meal was

5 significantly reduced, the size and duration of this meal was unaffected. Therefore, we

6 suggested that the ratio of non- $\Delta^{9} \mathrm{THC}$ pCBs present in the low- $\Delta^{9} \mathrm{THC}$ extract

7 significantly increased appetitive (but not consummatory behaviours), since the

8 concentrations of $\Delta^{9} \mathrm{THC}$ present were between two- and ten-fold lower than those

9 previously demonstrated to induce hyperphagia (Farrimond et al., 2010b).

10 When these two studies are considered together (Farrimond et al 2010a and

11 2010b), a number of suggestions can be made: firstly, since the observed effects of the

12 non- $\Delta \Delta^{9}$ THC components of the extracts administered reduced hyperphagia when

13 presented in one ratio and increased hyperphagia when presented in a different ratio, it

14 is highly unlikely that the plant matter also present was responsible for these effects,

15 given that its content did not change between the two tests. Secondly, it is possible that

16 the pCBs present in both studies did not act in isolation such that more than one

17 compound induced the observed effects. Thirdly, these effects could involve non-CBR

18 dependent pathways since several of the non- $\Delta^{9} \mathrm{THC}$ pCBs present are known to act via

19 mechanisms only partially connected to CBR (see Izzo et al., (2009) for review).

20 Finally, these results give further credence to the already well supported therapeutic

21 potential of non- $\Delta^{9} \mathrm{THC}$ pCBs for the treatment of energy balance disorders. Indeed,

22 non- $\Delta^{9} \mathrm{THC}$ pCB-based treatment may prove more tolerable than $\Delta^{9} \mathrm{THC}$ treatment

23 alone (e.g. Nabilone) due to the absence of psychotropic side effects associated with

24 non- $\Delta^{9} \mathrm{THC}$ pCBs. 
1 Whilst a definitive mechanism underlying the findings reported by Farrimond et

$2 a l$., (2010a and b) remains unknown, the naturally occurring $\mathrm{pCB}$ and $\mathrm{CB}_{1} \mathrm{R}$ neutral

3 antagonist $\Delta^{9} \mathrm{THCV}$, which was also present in the extracts employed in Farrimond et

$4 a l$., has been considered alone and shown to exert hypophagic actions (Riedel et al.,

5 2009). Indeed, given the difficulties associated with the use of the highly specific and

6 potent $\mathrm{CB}_{1} \mathrm{R}$ antagonist/inverse agonist SR141716A in the clinic, the use of $\Delta^{9} \mathrm{THCV}$,

7 as a neutral antagonist, to reduce food intake may be of therapeutic value. Riedel et al.

8 (2009) demonstrated that purified $\Delta^{9} \mathrm{THCV}(3.0,10.0$ and $30.0 \mathrm{mg} / \mathrm{kg}$; i.p.) significantly

9 reduced chow intake over a period 12 hours and induced weight loss in male C57BL6

10 mice. Subsequent treatment with extremely low $\Delta^{9}$ THCV BDS doses (which contained

11 between 0.1 and $0.3 \mathrm{mg} / \mathrm{kg} \Delta^{9} \mathrm{THC}$ ) failed to induce changes to feeding patters; however

12 the $\Delta^{9}$ THC quantities presented were within the range previously observed to affect

13 meal patterning in rats (Farrimond et al., 2010). Unfortunately, meal microstructure was

14 not analysed in this study. In a further experiment, Riedel hypothesised that if CBD

$15\left(10.0 \mathrm{mg} / \mathrm{kg}\right.$; i.p.) were to be co-administered with these very low $\Delta^{9} \mathrm{THCV}$ BDS doses,

16 the effects of the present $\Delta^{9} \mathrm{THC}$ would be antagonised, and the hypophagic properties

17 previously induced by purified $\Delta^{9} \mathrm{THCV}$ would therefore emerge. However, the

18 evidence for in vivo antagonism of $\Delta^{9} \mathrm{THC}$ by CBD has so far only been demonstrated

19 in a memory task (Fadda et al., 2004), and Riedel observed no significant effects on

20 feeding or weight change following CBD co-administration. The authors suggest that

21 this lack of effect may also be attributed to other pCBs, present in his extract, or simply

22 because the concentrations of $\Delta^{9} \mathrm{THCV}$ administered were too low. However, Riedel

23 recorded all feeding data during the light phase of the rats' day during which time little

24 feeding typically occurs. Furthermore, it is also possible that the experimental paradigm 
1 used was not optimised for the observation of hypophagia. For instance, introducing

2 food-deprivation prior to dosing could accentuate possible differences between control

3 and conditions measurements, thereby rendering the experimental paradigm more

4 sensitive to $\Delta^{9} \mathrm{THCV}$-mediated reductions in feeding. While, Riedel has confirmed that

5 purified $\Delta^{9} \mathrm{THCV}$ can reduce food intake in mice, further experiments which use more

6 sensitive paradigms and analyse meal microstructure after $\Delta^{9} \mathrm{THCV}$ BDS administration

7 may prove useful in fully understanding Riedel's data.

8 The work discussed throughout this manuscript demonstrates that some pCBs

9 can alter appetitive and consummatory behaviours separately (e.g. Higgs et al., 2003).

10 As such if it were possible to use at least one non- $\Delta^{9} \mathrm{THC}$ pCB to modulate

11 consummatory behaviours (to increase or decrease the quantity consumed during a

12 natural eating event) rather than inducing immediate short term post-administration

13 hunger (the 'munchies', a colloquial term meaning increased hunger normally due to

14 smoking cannabis recreationally) it may be possible to produce a $C$. sativa-based

15 medicine which could control absolute intake quantity. Even though the mechanisms by

16 which the $\mathrm{eCB}$ system modulates palatability and therefore diet selection remain

17 unclear, direct effects on diet selection caused by cannabinoid administration have also

18 been demonstrated. Given the presented data which suggests that increased eCB tone

19 leads to increased selection of fatty foods over sweet foods, it is a possibility that non-

20 psychotropic pCBs could also be used to modulate diet selection i.e. to reduce fatty food

21 palatability in obesity. Indeed, putative anti-obesity treatments using pCBs are of great

22 interest. Equally, while some pCBs have been shown to induce significant reductions in

23 food intake and in some cases reduce body weight (e.g. $\Delta^{9} \mathrm{THCV}$ ), little research is 
1 currently considering possible mechanisms by which intake and body weight may be 2 increased, which would be valuable in the treatment of anorectic disorders.

3

4 


\section{Conclusions}

2 A considerable quantity of characterisation work has been performed on $\Delta^{9} \mathrm{THC}$ -

3 mediated feeding effects, but the specific roles of other pCBs remain less well

4 understood. Work in our laboratory and others suggests that non- $\Delta^{9} \mathrm{THC}$ pCBs can have

5 profound effects on feeding behaviours (Farrimond et al., 2010a; Farrimond et al.,

6 2010b; Riedel et al., 2009; Sofia et al., 1976; Wiley et al., 2005). However, these are

7 not yet well characterised. As such considerable further work is required to assess the

8 effects of both purified single pCBs as well as combinations of numerous pCBs. With

9 the recent UK approval of the $\Delta^{9}$ THC CBD combination in Sativex, it can be clearly

10 seen that the use of $\mathrm{pCBs}$ in the clinic is gaining public acceptance that regulatory

11 bodies are willing to accept plant-derived medicines alongside their synthetic

12 counterparts. Indeed, non- $\Delta^{9} \mathrm{THC}$ pCBs may represent an untapped clinical potential for

13 a number of feeding disorders. Such a need is particularly important given the non-

14 specific behavioural side effects associated with the use of $\Delta^{9} \mathrm{THC}$ and its analogues in

15 the clinic. Given the encouraging results demonstrating non- $\Delta^{9} \mathrm{THC}$ pCB-mediated

16 modulation of feeding, it is tempting to suggest that these compounds may provide at

17 least the basis for novel therapies for the treatment of feeding disorders. 


\section{Acknowledgements}

2 The authors are grateful to the members of our research group who have kindly

3 commented on this manuscript, in particular to Drs A. Hill and G. Bucci. The authors

4 have no conflict of interest to declare.

5

6

7

8

9

10 


\section{References}

2 Adams R, Baker B (1940). Structure of Cannabidiol. VII. A Method of Synthesis of a

3 Tetrahydrocannabinol which Possesses Marihuana Activity1. J Am Chem Soc 62(9): $4 \quad 2405-2408$.

5

6

7

8

11

12

Agrawal A, Lynskey MT (2009). Candidate genes for cannabis use disorders: findings, challenges and directions. Addiction 104(4): 518-532.

Ahern G (2003). Activation of TRPV1 by the satiety factor oleoylethanolamide. J Biol Chem 278(33): 30429.

Alger BE (2009). Endocannabinoid Signaling in Neural Plasticity. edn, vol. 1. Springer Berlin Heidelberg.

Armstrong HE, Galka A, Lin LS, Lanza Jr TJ, Jewell JP, Shah SK, et al. (2007). Substituted acyclic sulfonamides as human cannabinoid-1 receptor inverse agonists. Bioorg Med Chem Lett 17(8): 2184-2187.

Arnone M, Maruani J, Chaperon F, Thiébot MH, Poncelet M, Soubrié P, et al. (1997). Selective inhibition of sucrose and ethanol intake by SR141716, an antagonist of central cannabinoid (CB1) receptors. Psychopharmacology 132(1): 104-106.

Avraham Y, Ben-Shushan D, Breuer A, Zolotarev O, Okon A, Fink N, et al. (2004). Very low doses of [Delta]8-THC increase food consumption and alter neurotransmitter levels following weight loss. Pharmacol Biochem Be77(4): 675-684.

Bachur N, Masek K, Melmon K, Udenfriend S (1965). Fatty acid amides of ethanolamine in mammalian tissues. J Biol Chem 240(3): 1019.

Baker D, Pryce G, Davies WL, Hiley CR (2006). In silico patent searching reveals a new cannabinoid receptor. Trends Pharmacol Sci 27(1): 1-4.

Baker D, Pryce G, Giovannoni G, Thompson A (2003). The therapeutic potential of cannabis. Lancet Neurol 2: 291-296.

Barbano M, Castane A, Martin-Garcia E, Maldonado R (2009). Delta-9tetrahydrocannabinol enhances food reinforcement in a mouse operant conflict test. Psychopharmacology 205(3): 475-487. 
1 Basavarajappa BS (2007a). Critical Enzymes Involved in Endocannabinoid Metabolism.

$2 \quad$ Protein Peptide Lett 14(3): 237.

3

4

5

6

7

14

Basavarajappa BS (2007b). Neuropharmacology of the Endocannabinoid Signalling System - Molecular Mechanisms, Biological Actions and Synaptic Plasticity. Curr Neuropharmacol 5(2): 81-97.

Ben-Zvi Z, Mechoulam R, Burstein S (1970). Identification through synthesis of an active .DELTA.1(6)-tetrahydrocannabinol metabolite. J Am Chem Soc 92(11): 34683469.

Ben Amar M (2006). Cannabinoids in medicine: A review of their therapeutic potential. $J$ Ethnopharmacol 105(1-2): 1-25.

Berridge M (1995). Capacitative calcium entry. Biochem J 312(Pt 1): 1.

(1988). Inositol trisphosphate and calcium signaling. Cold Spring Harbor Symposia on Quantitative Biology. Cold Spring Harbor Laboratory Press. p 927.

Bisogno T, Ligresti A, Di Marzo V (2005). The endocannabinoid signalling system: Biochemical aspects. Pharmacol Biochem Be 81(2): 224-238.

Blankman JL, Simon GM, Cravatt BF (2007). A comprehensive profile of brain enzymes that hydrolyze the endocannabinoid 2-arachidonoylglycerol. Chem Biol 14(12): 1347-1356.

Bortolato M, Mangieri R, Fu J, Kim J, Arguello O, Duranti A, et al. (2007). Antidepressant-like activity of the fatty acid amide hydrolase inhibitor URB597 in a rat model of chronic mild stress. Biol Psychiat 62(10): 1103-1110.

Breivogel CS, Sim LJ, Childers SR (1997). Regional differences in cannabinoid receptor/G-protein coupling in rat brain. J Pharmacol Exp Ther 282(3): 1632-1642.

Brown A, J. , Wise A (2001). Identification of modulators of GPR55 activity: GlaxoSmithKline.

Brown AJ (2007). Novel cannabinoid receptors. Brit J Pharmacol 152(5): 567-575. 
1 Burkey TH, Quock RM, Consroe P, Roeske WR, Yamamura HI (1997). $\Delta^{9}$ 2 Tetrahydrocannabinol is a partial agonist of cannabinoid receptors in mouse brain. Eur $J$ 3 Pharmacol 323(2-3): 3-4.

4

5

6

7

8

9

10

11

12

13

14

15

16

18

19

20

21

22

23

24

25

26

27

29

30

31

32

Cadas H, di Tomaso E, Piomelli D (1997). Occurrence and biosynthesis of endogenous cannabinoid precursor, $\mathrm{N}$-arachidonoyl phosphatidylethanolamine, in rat brain. $J$ Neurosci 17(4): 1226.

Cahn RS (1933). Cannabis indica resin, part IV. The synthesis of some 2:2dimethyldibenzopyrans, and confirmation of the structure of cannabinol. J. Chem. Soc.: 1400-1405.

Chan W, Magnus K, Watson H (1976). The structure of cannabitriol. Cell Mol Life Sci 32(3): 283-284.

Childers SR, Breivogel CS (1998). Cannabis and endogenous cannabinoid systems. Drug Alchol Depen 51(1-2): 173-187.

Clark RT (2009). Annual Report Pursuant to Section 13 or 15(d) of the Securities Exchange Act of 1934 For the Fiscal Year Ended December 31, 2008. Washington: Merck \& Co., Inc.

Comelli F, Giagnoni G, Bettoni I, Colleoni M, Costa B (2007). The inhibition of monoacylglycerol lipase by URB602 showed an anti-inflammatory and anti-nociceptive effect in a murine model of acute inflammation. Brit J Pharmacol 152(5): 787-794.

Consroe P (1998). Brain cannabinoid systems as targets for the therapy of neurological disorders. Neurobiol Dis 5(6 Pt B): 534-551.

Costiniuk CT, Mills E, Cooper CL (2008). Evaluation of oral cannabinoid-containing medications for the management of interferon and ribavirin-induced anorexia, nausea and weight loss in patients treated for chronic hepatitis C virus. Can J Gastroenterol 22(4).

Cota D, Marsicano G, Lutz B, Vicennati V, Stalla GK, Pasquali R, et al. (2003a). Endogenous cannabinoid system as a modulator of food intake. Int J Obes Relat Metab Disord 27(3): 289-301.

Cota D, Marsicano G, Tschöp M, Grübler Y, Flachskamm C, Schubert M, et al. (2003b). The endogenous cannabinoid system affects energy balance via central orexigenic drive and peripheral lipogenesis. J Clin Invest 112(3): 423-431. 
Cota D, Tschop MH, Horvath TL, Levine AS (2006). Cannabinoids, opioids and eating behavior: the molecular face of hedonism? Brain Res Brain Res Rev 51(1): 85-107.

Cravatt BF, Giang DK, Mayfield SP, Boger DL, Lerner RA, Gilula NB (1996). Molecular characterization of an enzyme that degrades neuromodulatory fatty-acid amides. Nature 384(6604): 83-87.

Davis J, Levine M (1977). A model for the control of ingestion. Psychol Rev 84(4): $379-412$.

Davis M, Maida V, Daeninck P, Pergolizzi J (2007). The emerging role of cannabinoid neuromodulators in symptom management. Supportive care cancer 15(1): 63-71.

De Filippis Dea (2008). Effect of cannabidiol on sepsis-induced motility disturbances in mice: involvement of CB1 receptors and fatty acid amide hydrolase. Neurogastroenterol Motil 20: 919-927.

de Fonseca R (2005). The endocannabinoid system: physiology and pharmacology. Alcohol Alcoholism 40(1): 2.

De Petrocellis L, Di Marzo V (2009). Non-CB 1, Non-CB 2 Receptors for Endocannabinoids, Plant Cannabinoids, and Synthetic Cannabimimetics: Focus on Gprotein-coupled Receptors and Transient Receptor Potential Channels. J Neuroimmune Pharm: 1-19.

De Petrocellis L, Vellani V, Schiano-Moriello A, Marini P, Magherini PC, Orlando P, et al. (2008). Plant-derived cannabinoids modulate the activity of transient receptor potential channels of ankyrin type-1 (TRPA1) and melastatin type-8 (TRPM-8). $J$ Pharmacol Exp Ther.

Deadwyler SA, Hampson RE, Mu J, Whyte A, Childers S (1995). Cannabinoids modulate voltage sensitive potassium A-current in hippocampal neurons via a cAMPdependent process. J Pharmacol Exp Ther 273(2): 734-743.

Dennis I, Whalley BJ, Stephens GJ (2008). Effects of $\Delta^{9}$-tetrahydrocannabivarin on [35S] GTP $\gamma \mathrm{S}$ binding in mouse brain cerebellum and piriform cortex membranes. Brit $J$ Pharmacol 154(6): 1349-1358.

Deutsch D, Ueda N, Yamamoto S (2002). The fatty acid amide hydrolase (FAAH). Prostag Leukotr Ess 66(2-3): 201-210. 
14
Devane WA, Dysarz FA, Johnson MR, Melvin LS, Howlett AC (1988). Determination and characterization of a cannabinoid receptor in rat brain. Mol Pharmacol 34(5): 605613.

Devane WA, Hanus L, Breuer A, Pertwee RG, Stevenson LA, Griffin G, et al. (1992). Isolation and structure of a brain constituent that binds to the cannabinoid receptor. Science 258(5090): 1946-1949.

Dewey WL (1986). Cannabinoid pharmacology. Pharmacol Rev 38(2): 151-178.

Di Marzo V (2008). Targeting the endocannabinoid system: to enhance or reduce? Nat Rev Drug Discov 7(5): 438-455.

Di Marzo V, Bifulco M, De Petrocellis L (2004). The endocannabinoid system and its therapeutic exploitation. Nat Rev Drug Discov 3(9): 771-784.

Di Marzo V, Fontana A, Cadas H, Schinelli S, Cimino G, Schwartz JC, et al. (1994). Formation and inactivation of endogenous cannabinoid anandamide in central neurons. Nature 372(6507): 686-691.

Di Marzo V, Maccarrone M (2008). FAAH and anandamide: is 2-AG really the odd one out? Trends Pharmacol Sci 29(5): 229-233.

Di Marzo V, Petrosino S (2007). Endocannabinoids and the regulation of their levels in health and disease. Curr opin lipidol 18(2): 129.

Elmquist J, Elias C, Saper C (1999). From Lesions to Leptin: Review Hypothalamic Control of Food Intake and Body Weight. Neuron 22: 221-232.

EMA (2009). Procedural steps taken and scientific information after the authorisation Acomplia. In: EMEA/H/C/000666/A20/0012, Agency EM (ed) Vol. 2010. Brussels: European Union.

Engeli S, Böhnke J, Feldpausch M, Gorzelniak K, Janke J, Bátkai S, et al. (2005). Activation of the peripheral endocannabinoid system in human obesity. Diabetes 54(10): 2838.

Evans AT, Formukong E, Evans FJ (1987). Activation of phospholipase A2 by cannabinoids: Lack of correlation with CNS effects. FEBS Letters 211(2): 119-122. 
Fadda P, Robinson L, Fratta W, Pertwee R, Riedel G (2004). Differential effects of THC-or CBD-rich cannabis extracts on working memory in rats. Neuropharmacology 47(8): 1170-1179.

Farrimond J, Hill A, Whalley B, Williams C (2010a). Cannabis constituents modulate 9-tetrahydrocannabinol-induced hyperphagia in rats. Psychopharmacology 210(1): 97106.

Farrimond JA, Whalley BJ, Williams CM (2010b). A low $\Delta$ 9tetrahydrocannabinol cannabis extract induces hyperphagia in rats. Behav pharmacol in press.

Felder CC, Joyce KE, Briley EM, Mansouri J, Mackie K, Blond O, et al. (1995). Comparison of the pharmacology and signal transduction of the human cannabinoid CB1 and CB2 receptors. Mol Pharmacol 48(3): 443-450.

Fong TM, Guan X-M, Marsh DJ, Shen C-P, Stribling DS, Rosko KM, et al. (2007). Antiobesity Efficacy of a Novel Cannabinoid-1 Receptor Inverse Agonist, N-[(1S,2S)3-(4-Chlorophenyl)-2-(3-cyanophenyl)-1-methylpropyl]-2-methyl-2-\{[5(trifluoromethyl)pyridin-2-yl]oxy\}propanamide (MK-0364), in Rodents. J Pharmacol Exp Ther 321(3): 1013-1022.

Fredriksson R, Höglund PJ, Gloriam DEI, Lagerström MC, Schiöth HB (2003). Seven evolutionarily conserved human rhodopsin $\mathrm{G}$ protein-coupled receptors lacking close relatives. FEBS Letters 554(3): 381-388.

Freund TF, Katona I, Piomelli D (2003). Role of Endogenous Cannabinoids in Synaptic Signaling. Physiol. Rev. 83(3): 1017-1066.

Gaetani S, Fu J, Cassano T, Dipasquale P, Romano A, Righetti L, et al. (2010). The FatInduced Satiety Factor Oleoylethanolamide Suppresses Feeding through Central Release of Oxytocin. J Neurosci 30(24): 8096.

Gallate JE, Saharov T, Mallet PE, McGregor IS (1999). Increased motivation for beer in rats following administration of a cannabinoid CB1 receptor agonist. Eur J Pharmacol 370(3): 233-240.

Gaoni Y, Mechoulam R (1966). Cannabichromene, a new active principle in hashish. Chemical Communications (London) 1966(1): 20-21. 
1 Gaoni Y, Mechoulam R (1964a). Isolation, Structure, and Partial Synthesis of an Active

2 Constituent of Hashish. J Am Chem Soc 86(8): 1646-1647.

3

4

(1964b). The structure and synthesis of cannabigerol, a new hashish constituent. Chemistry Society; London.

6

Gardner A, Mallet PE (2006). Suppression of feeding, drinking, and locomotion by a putative cannabinoid receptor [']silent antagonist'. Eur J Pharmacol 530(1-2): 103-106.

Gatley S, Gifford A, Volkow N, Lan R, Makriyannis A (1996). 123I-labeled AM251: a radioiodinated ligand which binds in vivo to mouse brain cannabinoid CB1 receptors.

12 Eur J Pharmacol 307(3): 331-338.

13
Gerdeman GL, Ronesi J, Lovinger DM (2002). Postsynaptic endocannabinoid release is critical to long-term depression in the striatum. Nat Neurosci 5(5): 446-451.

Gill E, Paton W, Pertwee R (1970). Preliminary experiments on the chemistry and pharmacology of cannabis. Nature 228: 134-136.

Glass M (2001). The role of Cannabinoids in neurodegenerative diseases. Prog NeuroPsychoph 25(4): 743-765.

Glick SD, Milloy S (1972). Increased and decreased eating following THC administration. . Psychonom. Sci. 29(6).

Gomez R, Navarro M, Ferrer B, Trigo JM, Bilbao A, Del Arco I, et al. (2002). A Peripheral Mechanism for CB1 Cannabinoid Receptor-Dependent Modulation of Feeding. J. Neurosci. 22(21): 9612-9617.

Gong J, Onaivi E, Ishiguro H, Liu Q, Tagliaferro P, Brusco A, et al. (2006). Cannabinoid CB2 receptors: Immunohistochemical localization in rat brain. Brain Res 1071: 10-23.

Goutopoulos A, Makriyannis A (2002). From cannabis to cannabinergics: new therapeutic opportunities. Pharmacology and Therapeutics 95: 103-117.

Grant I, Cahn B (2005). Cannabis and endocannabinoid modulators: Therapeutic promises and challenges. Clin Neurosci Res 5: 185-199. 
Hao S, Avraham Y, Mechoulam R, Berry EM (2000). Low dose anandamide affects food intake, cognitive function, neurotransmitter and corticosterone levels in dietrestricted mice. Eur J Pharmacol 392(3): 147-156.

Henstridge C, Balenga N, Schröder R, Kargl J, Platzer W, Martini L, et al. (2010). GPR55 ligands promote receptor coupling to multiple signalling pathways. Brit $J$ Pharmacol 9999(9999).

Henstridge CM, Balenga NAB, Ford LA, Ross RA, Waldhoer M, Irving AJ (2009). The GPR55 ligand L-\{alpha\}-lysophosphatidylinositol promotes RhoA-dependent Ca2+ signaling and NFAT activation. The FASEB Journal 23(1): 183.

Herkenham M, Lynn AB, Johnson MR, Melvin LS, de Costa BR, Rice KC (1991). Characterization and localization of cannabinoid receptors in rat brain: a quantitative in vitro autoradiographic study. J Neurosci 11(2): 563-583.

Herkenham M, Lynn AB, Little MD, Johnson MR, Melvin LS, de Costa BR, et al. (1990). Cannabinoid receptor localization in brain. P Natl Acad Sci USA 87(5): 1932.

Higgs S, Williams CM, Kirkham TC (2003). Cannabinoid influences on palatability: microstructural analysis of sucrose drinking after $\Delta^{9}$-tetrahydrocannabinol, anandamide, 2-arachidonoyl glycerol and SR141716. Psychopharmacology 165(4): 370-377.

Hohmann AG, Suplita RL, Bolton NM, Neely MH, Fegley D, Mangieri R, et al. (2005). An endocannabinoid mechanism for stress-induced analgesia. Nature 435(7045): 11081112.

Holland ML, Allen JD, Arnold JC (2008). Interaction of plant cannabinoids with the multidrug transporter ABCC1 (MRP1). Eur J Pharmacol 591(1-3): 128-131.

Hollister LE (1986). Health aspects of cannabis. Pharmacol Rev 38(1): 1-20.

Horswill J, Bali U, Shaaban S, Keily J, Jeevaratnam P, Babbs A, et al. (2007). PSNCBAM-1, a novel allosteric antagonist at cannabinoid CB1 receptors with hypophagic effects in rats. Brit J Pharmacol 152(5): 805.

Hosohata K, Quock RM, Hosohata Y, Burkey TH, Makriyannis A, Consroe P, et al. (1997). AM630 is a competitive cannabinoid receptor antagonist in the guinea pig brain. Life Sci 61(9): PL115-118. 
1 Howlett AC (2002). The cannabinoid receptors. Prostaglandins Other Lipid Mediat 682 69: 619-631.

3

4

5

6

7

14

Howlett AC, Bidaut-Russell M, Devane WA, Melvin LS, Johnson MR, Herkenham M (1990). The cannabinoid receptor: biochemical, anatomical and behavioral characterization. Trends Neurosci 13(10): 420-423.

Howlett AC, Breivogel CS, Childers SR, Deadwyler SA, Hampson RE, Porrino LJ (2004). Cannabinoid physiology and pharmacology: 30 years of progress. Neuropharmacology 47(Supplement 1): 345-358.

Huffman J, Dai D, Martin B, Compton D (1994). Design, Synthesis and Pharmacology of Cannabimimetic Indoles. Bioorg Med Chem Lett 4: 563-566.

Hughes TE (2009). Emerging therapies for metabolic diseases--the focus is on diabetes and obesity. Curr Opin Chem Biol In Press, Corrected Proof.

Ishiguro H, Onaivi ES, Horiuchi Y, Imai K, Komaki G, Ishikawa T, et al. (2010). Functional polymorphism in the GPR55 gene is associated with anorexia nervosa. Synapse: Epub ahead of print.

Izzo AA, Borrelli F, Capasso R, Di Marzo V, Mechoulam R (2009). Non-psychotropic plant cannabinoids: new therapeutic opportunities from an ancient herb. Trends Pharmacol Sci 30(10): 515-527.

Jamshidi N, Taylor DA (2001). Anandamide administration into the ventromedial hypothalamus stimulates appetite in rats. Brit J Pharmacol 134(6): 1151-1154.

Jarrett MM, Limebeer CL, Parker LA (2005). Effect of [Delta]9-tetrahydrocannabinol on sucrose palatability as measured by the taste reactivity test. Physio Behav 86(4): 475479 .

Jarrett MM, Scantlebury J, Parker LA (2007). Effect of [Delta]9-tetrahydrocannabinol on quinine palatability and AM251 on sucrose and quinine palatability using the taste reactivity test. Physio Behav 90(2-3): 425-430.

Jin X, Okamoto Y, Morishita J, Tsuboi K, Tonai T, Ueda N (2007). Discovery and characterization of a $\mathrm{Ca} 2+-i n d e p e n d e n t$ phosphatidylethanolamine $\mathrm{N}$-acyltransferase generating the anandamide precursor and its congeners. J Biol Chem 282(6): 3614. 
14

Kapur A, Zhao P, Sharir H, Bai Y, Caron M, Barak L, et al. (2009). Atypical responsiveness of the orphan receptor GPR55 to cannabinoid ligands. J Biol Chem 284(43): 29817.

King A, Duranti A, Tontini A, Rivara S, Rosengarth A, Clapper J, et al. (2007). URB602 inhibits monoacylglycerol lipase and selectively blocks 2arachidonoylglycerol degradation in intact brain slices. Chem Biol 14(12): 1357-1365.

Kirby MT, Hampson RE, Deadwyler SA (2000). Cannabinoid receptor activation in CA1 pyramidal cells in adult rat hippocampus. Brain Res 863(1-2): 120-131.

Kirkham T, Williams C (2001a). Endocannabinoids: neuromodulators of food craving. Food Cravings and Addiction. Leatherhead: Leatherhead Publishing: 85-120.

Kirkham TC (2008). Endocannabinoids and the Neurochemistry of Gluttony. $J$ Neuroendocrinol 20(9): 1099-1100.

Kirkham TC, Williams CM (2001b). Endogenous cannabinoids and appetite. Nutr Res 14(01): 65-86.

Kirkham TC, Williams CM (2001c). Synergistic efects of opioid and cannabinoid antagonists on food intake. Psychopharmacology 153(2): 267-270.

Kirkham TC, Williams CM, Fezza F, Di Marzo V (2002). Endocannabinoid levels in rat limbic forebrain and hypothalamus in relation to fasting, feeding and satiation: stimulation of eating by 2-arachidonoyl glycerol. Br J Pharmacol 136(4): 550-557.

Koch JE (2001). [Delta]9-THC stimulates food intake in Lewis rats: effects on chow, high-fat and sweet high-fat diets. Pharmacol Biochem Be68(3): 539-543.

Lambert D, Fowler C (2005). The endocannabinoid system: drug targets, lead compounds, and potential therapeutic applications. J. Med. Chem 48(16): 5059-5087.

Landsman RS, Burkey TH, Consroe P, Roeske WR, Yamamura HI (1997). SR141716A is an inverse agonist at the human cannabinoid CB1 receptor. Eur J Pharmacol 334(1): R1-2.

Lauckner JE, Hille B, Mackie K (2005). The cannabinoid agonist WIN55,212-2 increases intracellular calcium via $\mathrm{CB} 1$ receptor coupling to $\mathrm{Gq} / 11 \mathrm{G}$ proteins. Proc Natl Acad Sci USA 102(52): 19144-19149. 
Lauckner JE, Jensen JB, Chen HY, Lu HC, Hille B, Mackie K (2008). GPR55 is a cannabinoid receptor that increases intracellular calcium and inhibits $\mathrm{M}$ current. Proc Natl Acad Sci USA 105(7): 2699.

Ligresti A, Moriello A, Starowicz K, Matias I, Pisanti S, De Petrocellis L, et al. (2006). Antitumor activity of plant cannabinoids with emphasis on the effect of cannabidiol on human breast carcinoma. J Pharmacol Exp Ther 318(3): 1375.

Little P, Compton D, Johnson M, Melvin L, Martin B (1988). Pharmacology and stereoselectivity of structurally novel cannabinoids in mice. J Pharmacol Exp Ther 247(3): 1046.

Liu J, Wang L, Harvey-White J, Huang BX, Kim HY, Luquet S, et al. (2008). Multiple pathways involved in the biosynthesis of anandamide. Neuropharmacology 54(1): 1-7.

Long J, Li W, Booker L, Burston J, Kinsey S, Schlosburg J, et al. (2009). Selective blockade of 2-arachidonoylglycerol hydrolysis produces cannabinoid behavioral effects. Nat chem biol 5(1): 37.

Ma Y, Weston S, Whalley B, Stephens G (2007). Cannabinoid-induced modulation of cerebellar output occurs via effects on fast inhibittory synaptic transmission. $J$. Neurosci.

Ma YL, Weston SE, Whalley BJ, Stephens GJ (2008). The phytocannabinoid $\Delta^{9}$ tetrahydrocannabivarin modulates inhibitory neurotransmission in the cerebellum. Brit $J$ Pharmacol 154(1): 204-215.

Maccarrone M (2009). Endocannabinoids: Friends and foes of reproduction. Prog Lipid Res 48(6): 344-354.

Maccarrone M, Gasperi V, Catani M, Diep T, Dainese E, Hansen H, et al. (2010). The Endocannabinoid System and Its Relevance for Nutrition. Ann Rev Nut 30.

Mackie K (2005). Distribution of cannabinoid receptors in the central and peripheral nervous system. In: Pertwee R (ed)^(eds). Cannabinoids, edn, Vol. 168. Berlin: Springer-Verlag. $\mathrm{p}^{\wedge} \mathrm{pp}$ 299-325.

Mackie K (2006). Mechanisms of CB1 receptor signaling: endocannabinoid modulation of synaptic strength. Int J Obes (Lond) 30 Suppl 1: S19-23. 
Makriyannis A, Mechoulam R, Piomelli D (2005). Therapeutic opportunities through modulation of the endocannabinoid system. Neuropharmacology 48(8): 1068-1071.

(2002). Agonists and silent antagonists in a series of cannabinoid sulfonamides. International Cannabinoid Research Society Conference; Pacific Grover, California, USA. ICRS.

Mathes CM, Ferrara M, Rowland NE (2008). Cannabinoid-1 receptor antagonists reduce caloric intake by decreasing palatable diet selection in a novel dessert protocol in female rats. Am J Physiol-Reg I 295(1): R67.

Matsuda LA, Lolait SJ, Brownstein MJ, Young AC, Bonner TI (1990). Structure of a cannabinoid receptor and functional expression of the cloned cDNA. Nature 346(6284): 561-564.

Mechoulam R, Ben-Shabat S, Hanus L, Ligumsky M, Kaminski NE, Schatz AR, et al. (1995a). Identification of an endogenous 2-monoglyceride, present in canine gut, that binds to cannabinoid receptors. Biochem Pharmacol 50(1): 83-90.

Mechoulam R, Ben-Shabat S, Hanus L, Ligumsky M, Kaminski NE, Schatz AR, et al. (1995b). Identification of an endogenous 2-monoglyceride, present in canine gut, that binds to cannabinoid receptors. Biochem Pharmacol 50(1): 83-90.

Melvin LS, Johnson MR, Milne GM (1983). A cannabinoid derived analgetic (CP55,940) Abstract. In: 186th National Meeting of the American Chemical Society. Washington: American Chemical Society.

Moldrich G, Wenger T (2000). Localization of the $\mathrm{CB}_{1}$ cannabinoid receptor in the rat brain. An immunohistochemical study. Peptides 21(11): 1735-1742.

Morgan NH, Stanford IM, Woodhall GL (2009). Functional CB2 type cannabinoid receptors at CNS synapses. Neuropharmacology 57(4): 356-368.

Morley J, Levine A (1982). The role of the endogenous opiates as regulators of appetite. Am J Clin Nut 35(4): 757.

Munro S, Thomas KL, Abu-Shaar M (1993). Molecular characterization of a peripheral receptor for cannabinoids. Nature 365(6441): 61-65. 
1 Naidu P, Kinsey S, Guo T, Cravatt B, Lichtman A (2010). Regulation of Inflammatory

2 Pain by Inhibition of Fatty Acid Amide Hydrolase. J Pharmacol Exp Ther 334(1): 182.

3

4

5

6

7

Ning Y, Neill KO, Lan H, Pang L, Shan LX, Hawes BE, et al. (2008). Endogenous and synthetic agonists of GPR119 differ in signalling pathways and their effects on insulin secretion in MIN6c4 insulinoma cells. Brit J Pharmacol 155(7): 1056-1065.

Ohno-Shosaku T, Maejima T, Kano M (2001). Endogenous cannabinoids mediate retrograde signals from depolarized postsynaptic neurons to presynaptic terminals. Neuron 29(3): 729-738.

Okamoto K, Wang J, Morishita J, Ueda N (2009a). Biosynthetic Pathways of the Endocannabinoid Anadamide. In: Lambert DM (ed)^(eds). Cannabinoids in Nature and Medicine, edn. Zurich and Weinheim: VHCA and WILEY-VCH. $\mathrm{p}^{\wedge} \mathrm{pp}$ 267-320.

Okamoto Y, Morishita J, Tsuboi K, Tonai T, Ueda N (2004). Molecular characterization of a phospholipase D generating anandamide and its congeners. J Biol Chem 279(7): 5298-5305.

Okamoto Y, Tsuboi K, Ueda N (2009b). Chapter 1 Enzymatic Formation of Anandamide. In: Gerald L (ed)^(eds). Vitamins \& Hormones, edn, Vol. Volume 81: Academic Press. p^pp 1-24.

Onaivi E, Carpio O, Ishiguro H, Schanz N, Uhl G, Benno R (2008). Behavioral effects of CB2 cannabinoid receptor activation and its influence on food and alcohol consumption. Ann. NY Acad. Sci 1139: 426-433.

Onaivi E, Ishiguro H, Gong J, Patel S, Perchuk A, Meozzi P, et al. (2006). Discovery of the Presence and Functional Expression of Cannabinoid CB2 Receptors in Brain. Ann. N.Y. Acad. Sci.(1074): 514-536.

Onaivi E, Leonard C, Ishiguro H, Zhang P, Lin Z, Akinshola B, et al. (2002). Endocannabinoids and cannabinoid receptor genetics. Progress in Neurobiol 66: 307344.

Osei-Hyiaman D, DePetrillo M, Pacher P, Liu J, Radaeva S, Batkai S, et al. (2005). Endocannabinoid activation at hepatic CB1 receptors stimulates fatty acid synthesis and contributes to diet-induced obesity. J Clin Invest 115(5): 1298-1305. 
1 Overton HA, Babbs AJ, Doel SM, Fyfe MCT, Gardner LS, Griffin G, et al. (2006). 2 Deorphanization of a $G$ protein-coupled receptor for oleoylethanolamide and its use in 3 the discovery of small-molecule hypophagic agents. Cell Metabol 3(3): 167-175.

4

5

6

7

8

14

Overton HA, Fyfe MCT, Reynet C (2008). GPR119, a novel G protein-coupled receptor target for the treatment of type 2 diabetes and obesity. Brit J Pharmacol 153(S1): S76S81.

Oz M (2006). Receptor-independent effects of endocannabinoids on ion channels. Curr Pharm Des 12(2): 227-239.

Pacheco M, Childers S, Arnold R, Casiano F, Ward S (1991). Aminoalkylindoles: actions on specific G-protein-linked receptors. J Pharmacol Exp Ther 257(1): 170.

Pertwee R (2001). Cannabinoid receptor ligands. Tocris Rev 16: 1-8.

Pertwee R, Griffin G, Fernando S, Li X, Hill A, Makriyannis A (1995). AM630, a competitive cannabinoid receptor antagonist. Life Sci 56(23-24): 1949-1955.

Pertwee R, Joe-Adigwe G, Hawksworth G (1996). Further evidence for the presence of cannabinoid CB1 receptors in mouse vas deferens. Eur J Pharmacol 296(2): 169-172.

Pertwee RG (2008a). The diverse CB1 and CB2 receptor pharmacology of three plant cannabinoids: $\Delta^{9}$-tetrahydrocannabinol, cannabidiol and $\Delta^{9}$-tetrahydrocannabivarin. Brit J Pharmacol 153(2): 199-215.

Pertwee RG (2008b). The diverse $\mathrm{CB}_{1}$ and $\mathrm{CB}_{2}$ receptor pharmacology of three plant cannabinoids: $\Delta^{9}$-tetrahydrocannabinol, cannabidiol and $\Delta^{9}$-tetrahydrocannabivarin. Brit J Pharmacol 153(2): 199-215.

Pertwee RG (2007). GPR55: a new member of the cannabinoid receptor clan? Brit J Pharmacol 152(7): 984-986.

Pertwee RG (1999). Pharmacology of cannabinoid receptor ligands. Curr Med Chem 6(8): 635-664.

Pertwee RG (2005). The therapeutic potential of drugs that target cannabinoid receptors or modulate the tissue levels or actions of endocannabinoids. Aaps J 7(3): E625-654. 
1 Petitet F, Donlan M, Michel A (2006). GPR55 as a new cannabinoid receptor: still a

2 long way to prove it. Chem Biol Drug Des 67(3): 252-253.

3

4

5

6

Petrosino S, Ligresti A, Di Marzo V (2009). Endocannabinoid chemical biology: a tool for the development of novel therapies. Curr Opin Chem Bio 13(3): 309-320.

Pietr M, Kozela E, Levy R, Rimmerman N, Lin YH, Stella N, et al. (2009). Differential changes in GPR55 during microglial cell activation. FEBS Letters 583(12): 2071-2076.

Piomelli D (2003). The molecular logic of endocannabinoid signalling. Nat Rev Neurosci 4(11): 873-884.

Piomelli D, Giuffrida A, Calignano A, Rodriguez de Fonseca F (2000). The endocannabinoid system as a target for therapeutic drugs. Trends Pharmacol Sci 21(6): 218-224.

Piomelli D, Tarzia G, Duranti A, Tontini A, Mor M, Compton TR, et al. (2006). Pharmacological profile of the selective FAAH inhibitor KDS-4103 (URB597). CNS Drug Rev 12(1): 21-38.

Pope C, Mechoulam R, Parsons L (2010). Endocannabinoid signaling in neurotoxicity and neuroprotection. Neurotox In Press, Corrected Proof.

Pryce G, Ahmed Z, Hankey D, Jackson S, Croxford J, Pocock J, et al. (2003). Cannabinoids inhibit neurodegeneration in models of multiple sclerosis. Brain 126: 2191-2202.

Pryce G, Baker D (2005). Emerging properties of cannabinoid medicines in management of multiple sclerosis. Trends Neurosci 28(5): 272-276.

Putney Jr J (1986). A model for receptor-regulated calcium entry. Cell Calcium 7(1): 112.

Rao GK, Kaminski NE (2006). Cannabinoid-mediated elevation of intracellular calcium: a structure-activity relationship. J Pharmacol Exp Ther 317(2): 820-829.

Riedel G, Fadda P, McKillop-Smith S, Pertwee R, Platt B, Robinson L (2009). Synthetic and plant-derived cannabinoid receptor antagonists show hypophagic properties in fasted and non-fasted mice. Brit J Pharmacol 156(7): 1154-1166. 
Rinaldi-Carmona M, Barth F, Heaulme M, Shire D, Calandra B, Congy C, et al. (1994). SR141716A, a potent and selective antagonist of the brain cannabinoid receptor. FEBS Lett 350(2-3): 240-244.

Rinaldi-Carmona M, Barth F, Millan J, Derocq J, Casellas P, Congy C, et al. (1998). SR 144528 , the first potent and selective antagonist of the CB2 cannabinoid receptor. $J$ Pharmacol Exp Ther 284(2): 644.

Rodriguez de Fonseca F, Navarro M, Gomez R, Escuredo L, Nava F, Fu J, et al. (2001). An anorexic lipid mediator regulated by feeding. Nature 414(6860): 209-212.

Ronesi J, Gerdeman GL, Lovinger DM (2004). Disruption of Endocannabinoid Release and Striatal Long-Term Depression by Postsynaptic Blockade of Endocannabinoid Membrane Transport. J. Neurosci. 24(7): 1673-1679.

Ross RA (2009). The enigmatic pharmacology of GPR55. Trends Pharmacol Sci 30(3): 156-163.

Ross RA, Brockie HC, Stevenson LA, Murphy VL, Templeton F, Makriyannis A, et al. (1999). Agonist-inverse agonist characterization at CB1 and CB2 cannabinoid receptors of L759633, L759656, and AM630. Brit J Pharmacol 126(3): 665-672.

Ryan D, Drysdale AJ, Lafourcade C, Pertwee RG, Platt B (2009). Cannabidiol Targets Mitochondria to Regulate Intracellular Ca2+ Levels. J. Neurosci. 29(7): 2053-2063.

Ryberg E, Larsson N, Sjögren S, Hjorth S, Hermansson NO, Leonova J, et al. (2007). The orphan receptor GPR55 is a novel cannabinoid receptor. Brit J Pharmacol 152(7): 1092-1101.

Sanger GJ (2007). Endocannabinoids and the gastrointestinal tract: what are the key questions? Brit J Pharmacol 152(5): 663-670.

Sawzdargo M, Nguyen T, Lee DK, Lynch KR, Cheng R, Heng HH, et al. (1999). Identification and cloning of three novel human $G$ protein-coupled receptor genes GPR52, PsiGPR53 and GPR55: GPR55 is extensively expressed in human brain. Brain Res Mol Brain Res 64(2): 193-198.

Schweitzer P (2000). Cannabinoids decrease the K(+) M-current in hippocampal CA1 neurons. J Neurosci 20(1): 51-58. 
1

2

3

4

5

6

7

8

9

10

11

12

13

14

15

16

17

18

Showalter V, Compton D, Martin B, Abood M (1996). Evaluation of binding in a transfected cell line expressing a peripheral cannabinoid receptor (CB2): identification of cannabinoid receptor subtype selective ligands. J Pharmacol Exp Ther 278(3): 989.

Simiand J, Keane M, Keane P, Soubrie P (1998). SR 141716, a CB1 cannabinoid receptor antagonist, selectively reduces sweet food intake in marmoset. Behav Pharmacol 9(2): 179.

Sink K, McLaughlin P, Wood J, Brown C, Fan P, Vemuri V, et al. (2007). The novel cannabinoid CB1 receptor neutral antagonist AM4113 suppresses food intake and foodreinforced behavior but does not induce signs of nausea in rats. Neuropsychopharmacol 33(4): 946-955.

Sofia RD, Knobloch LC (1976). Comparative effects of various naturally occurring cannabinoids on food, sucrose and water consumption by rats. Pharmacol Biochem Be4(5): 591-599.

Soga T, Ohishi T, Matsui T, Saito T, Matsumoto M, Takasaki J, et al. (2005). Lysophosphatidylcholine enhances glucose-dependent insulin secretion via an orphan G-protein-coupled receptor. Biochem Bioph Res Co 326(4): 744-751.

Solinas M, Goldberg S (2005). Motivational effects of cannabinoids and opioids on food reinforcement depend on simultaneous activation of cannabinoid and opioid systems. Neuropsychopharmacol 30(11): 2035-2045.

Staton PC, Hatcher JP, Walker DJ, Morrison AD, Shapland EM, Hughes JP, et al. (2008). The putative cannabinoid receptor GPR55 plays a role in mechanical hyperalgesia associated with inflammatory and neuropathic pain. Pain 139(1): 225-236.

Stratford TR, Kelley AE (1999). Evidence of a Functional Relationship between the Nucleus Accumbens Shell and Lateral Hypothalamus Subserving the Control of Feeding Behavior. J. Neurosci. 19(24): 11040-11048.

Südhof TC, Starke K (2008). Pharmacology of neurotransmitter release. edn. Springer Verlag.

Sugiura T, Kodaka T, Nakane S, Miyashita T, Kondo S, Suhara Y, et al. (1999). Evidence that the cannabinoid CB1 receptor is a 2-arachidonoylglycerol receptor. J Biol Chem 274(5): 2794. 
1 Sugiura T, Kondo S, Sukagawa A, Nakane S, Shinoda A, Itoh K, et al. (1995). 22 Arachidonoylglycerol: a possible endogenous cannabinoid receptor ligand in brain.

3 Biochem Biophys Res Commun 215(1): 89-97.

4

5

6

7

Sugiura T, Waku K (2000). 2-Arachidonoylglycerol and the cannabinoid receptors. Chem Phys Lipids 108(1-2): 89-106.

Takeda S, Misawa K, Yamamoto I, Watanabe K (2008). Cannabidiolic Acid as a Selective Cyclooxygenase-2 Inhibitory Component in Cannabis. Drug Metab Dispos 36(9): 1917-1921.

Thomas A, Stevenson LA, Wease KN, Price MR, Baillie G, Ross RA, et al. (2005). Evidence that the plant cannabinoid $\Delta^{9}$-tetrahydrocannabivarin is a cannabinoid $\mathrm{CB}_{1}$ and $\mathrm{CB}_{2}$ receptor antagonist. Brit J Pharmacol 7(146): 917-926.

Thornton-Jones Z, Kennett G, Vickers S, Clifton P (2007). A comparison of the effects of the CB 1 receptor antagonist SR141716A, pre-feeding and changed palatability on the microstructure of ingestive behaviour. Psychopharmacology 193(1): 1-9.

Tramer M, Carroll D, Campbell F, Reynolds D, Moore R, McQuay H (2001). Cannabinoids for control of chemotherapy induced nausea and vomiting: quantitative systematic. Brit Med J 323(7303): 16.

Tsou K, Brown S, Sa udo-Pe a M, Mackie K, Walker J (1997). Immunohistochemical distribution of cannabinoid CB1 receptors in the rat central nervous system. Neurosci 83(2): 393-411.

Turu G, Hunyady L (2009). Signal transduction of the CB1 cannabinoid receptor. J Mol Endocrin. 44: 75-85

Van Gaal LF, Rissanen AM, Scheen AJ, Ziegler O, Rössner S (2005). Effects of the cannabinoid-1 receptor blocker rimonabant on weight reduction and cardiovascular risk factors in overweight patients: 1-year experience from the RIO-Europe study. Lancet 365(9468): 1389-1397.

Van Sickle MD, Duncan M, Kingsley PJ, Mouihate A, Urbani P, Mackie K, et al. (2005). Identification and functional characterization of brainstem cannabinoid CB2 receptors. Science 310(5746): 329-332.

Vandevoorde S (2008). Overview of the chemical families of fatty acid amide hydrolase and monoacylglycerol lipase inhibitors. Curr Top Med Chem 8(3): 247-267. 
Walsh DM, Nelson KA, Mahmoud F (2003). Established and potential therapeutic applications of cannabinoids in oncology. Supportive care cancer 11(3): 137-143.

Wang T, Collet J, Shapiro S, Ware M (2008). Adverse effects of medical cannabinoids: a systematic review. Can Med Assoc J 178(13): 1669.

Werner N, Koch J (2003). Effects of the cannabinoid antagonists AM281 and AM630 on deprivation-induced intake in Lewis rats. Brain Res 967(1-2): 290-292.

Whalley BJ, Wilkinson JD, Williamson EM, Constanti A (2004). A novel component of cannabis extract potentiates excitatory synaptic transmission in rat olfactory cortex in vitro. Neurosci Lett 365(1): 58-63.

Wiley J, Burston J, Leggett D, Alekseeva O, Razdan R, Mahadevan A, et al. (2005). CB1 cannabinoid receptor-mediated modulation of food intake in mice. Brit $J$ Pharmacol 145(3): 293-300.

Wilkinson JD, Whalley BJ, Baker D, Pryce G, Constanti A, Gibbons S, et al. (2003). Medicinal cannabis: is delta9-tetrahydrocannabinol necessary for all its effects? $J$ Pharm Pharmacol 55(12): 1687-1694.

Williams CM, Kirkham TC (1999). Anandamide induces overeating: mediation by central cannabinoid $\mathrm{CB}_{1}$ receptors. Psychopharmacology 143(3): 315-317.

Williams CM, Kirkham TC (2002a). Observational analysis of feeding induced by Delta9-THC and anandamide. Physiol Behav 76(2): 241-250.

Williams CM, Kirkham TC (2002b). Reversal of $\Delta^{9}$-THC hyperphagia by SR141716 and naloxone but not dexfenfluramine. Pharmacol Biochem Be 71(1-2): 333-340.

Williams CM, Rogers PJ, Kirkham TC (1998). Hyperphagia in pre-fed rats following oral $\Delta^{9}$-THC. Physiol Behav 65(2): 343-346.

Williamson EM, Evans FJ (2000). Cannabinoids in clinical practice. Drugs 60(6): 1303.

Wilson RI, Nicoll RA (2001). Endogenous cannabinoids mediate retrograde signalling at hippocampal synapses. Nature 410(6828): 588-592. 
1 Woolridge E, Barton S, Samuel J, Osorio J, Dougherty A, Holdcroft A (2005). Cannabis 2 use in HIV for pain and other medical symptoms. J Pain Symptom manag 29(4): 3583367.

4

5 Yamauchi T, Shoyama Y, Aramaki H, Azuma T, Nishioka I (1967).

6 Tetrahydrocannabinolic acid, a genuine substance of tetrahydrocannabinol. Chem

7 Pharm Bull 15(7): 1075.

8

Yan L, Huo P, Debenham JS, Madsen-Duggan CB, Lao J, Chen RZ, et al. (2010). Discovery of N-[(4R)-6-(4-Chlorophenyl)-7-(2,4-dichlorophenyl)-2,2-dimethyl-3,4dihydro-2H-pyrano[2,3-b]pyridin-4-yl]-5-methyl-1H-pyrazole-3-carboxamide (MK5596) as a Novel Cannabinoid-1 Receptor (CB1R) Inverse Agonist for the Treatment of Obesity. J Med Chem. 53(10):4028-37.

Yates ML, Barker EL (2009). Inactivation and Biotransformation of the Endogenous Cannabinoids Anandamide and 2-Arachidonoylglycerol. Mol Pharmaco 76(1): 11.

Yoshida R, Ohkuri T, Jyotaki M, Yasuo T, Horio N, Yasumatsu K, et al. (2010). Endocannabinoids selectively enhance sweet taste. P Natl Acad Sci USA 107(2): 935939.

Zhu HJ, Wang JS, Markowitz JS, Donovan JL, Gibson BB, Gefroh HA, et al. (2006). Characterization of P-glycoprotein inhibition by major cannabinoids from marijuana. $J$ Pharmacol Exp Ther 317(2): 850-857. 
$1 \quad$ Figure 1; the development of cannabinoid pharmacology $1964-2010$.

2 Figure 2; eCB signalling pathways. Upon invasion of an action potential into the

3 synaptic region of the presynapse, the release of neurotransmitter (in this case glutamate

4 or acetylcholine) and the binding of neurotransmitter to postsynaptic receptor sites: the

5 eCBs AEA and 2-AG are produced on demand from arachidonic acid by NaPE and

6 DAG respectively and released into the synaptic cleft from the postsynapse (red). Upon

7 neurotransmitter binding to both metabotropic Glutamate and Acetylcholine receptors $G$

8 subunits disassociate and stimulate an increase in PLC- $\beta$ levels. This leads to an

9 upregulation of intracellular $\mathrm{IP}_{3}$ which gates calcium channels on the endoplasmic

10 reticulum thus increasing intracellular $\mathrm{Ca}^{2+}$. Furthermore, the release of $\mathrm{G}_{\text {ai/o }}$ subunits

11 upregulates the production of cAMP and therefore allows further $\mathrm{Ca}^{2+}$ entry into the cell

12 via VGCCs. Equally upon activation of iGluR channels calcium is allowed into the cell.

13 Once released into the extracellular space the endocannabinoids bind to $\mathrm{CB}_{1} \mathrm{R}$ sites on

14 the presynapse (green) causing the presynaptic cell to move closer to its resting

15 membrane potential principally by closing VGCCs and opening VGPCs thus reducing

16 the available intracellular $\mathrm{Ca}^{2+}$ required to facilitate further neurotransmitter release.

17 Figure 3; simplified diagram illustrating retrograde signalling by eCBs in the CNS.

18 Following vesicular neurotransmitter release from the presynaptic cell (green),

19 neurotransmitters bind to receptor proteins (black) on the postsynaptic cell (red)

20 stimulating eCB production and release from the postsynaptic cell. eCBs then diffuse

21 back across the synaptic cleft and bind to CBRs (blue) on the presynaptic cell. This

22 predominately leads to a suppression of $\left[\mathrm{Ca}^{+}\right]$influx but also an increase in $\left[\mathrm{K}^{+}\right]$efflux,

23 thus hyperpolarising the presynaptic cell and inhibiting further neurotransmitter release. 
1 Table 1; endocannabinergic tone effecter ligands. A brief overview of the CBR ligands

2 discussed throughout this review, giving further background to their discovery and

3 where appropriate their non-feeding effects.

4 Abbreviations: 2-AG, 2-archidonlyglycerol; $\Delta^{8} \mathrm{THC}, \Delta^{8}$ tetrahydrocannabinol; $\Delta^{9} \mathrm{THC}$,

$5 \quad \Delta^{9}$ tetrahydrocannabinol; $\quad \Delta^{9}$ THCA, $\quad \Delta^{9}$ tetrahydrocannbinolic acid; $\quad \Delta^{9} \mathrm{THCV}$,

$6 \Delta^{9}$ tetrahydrocannbivarin; AEA, anandamide; $\mathrm{CB}_{1} \mathrm{R}$, cannabinoid type 1 receptor; $\mathrm{CB}_{2} \mathrm{R}$,

7 cannabinoid type 2 receptor; CBR, cannabinoid receptor; CNS, central nervous system;

8 FAAH, fatty acid amide hydrolase; MAGL, monoacylglycerol lipase; OEA, n-

9 oleoylethanolamide; P-gp, p-glycoprotein; $\mathrm{VR}_{1}$, transient receptor potential vanniliod 1;

$10 \quad \mathrm{TRPA}_{1}$, transient receptor potential cation channel, subfamily A, member 1. 